\title{
PADRÕES DE VIAGENS INTRAURBANAS PARA O TRABALHO E ESTABELECIMENTOS EDUCACIONAIS: EVIDÊNCIAS A PARTIR DO ESTUDO DE CASO DE UBERLÂNDIA - MG
}

\author{
Fernando Garrefa \\ Universidade Federal de Uberlândia \\ Faculdade de Arquitetura e Urbanismo e Design, Uberlândia, MG, Brasil \\ fegarrefa@yahoo.com \\ Flávia Fernandes Carvalho \\ Universidade Federal de Uberlândia \\ Faculdade de Arquitetura e Urbanismo e Design, Pós-graduação em Arquitetura e Urbanismo, Uberlândia, MG, \\ Brasil \\ flaviaudia@gmail.com \\ Júlia Tavares de Sousa Elias \\ Universidade Federal de Uberlândia \\ Faculdade de Arquitetura e Urbanismo e Design, Graduação em Arquitetura e Urbanismo, Uberlândia, MG, Brasil \\ juliattavares19@gmail.com \\ Isabella Denadae de Campos Pinto \\ Universidade Federal de Uberlândia \\ Faculdade de Arquitetura e Urbanismo e Design, Graduação em Arquitetura e Urbanismo, Uberlândia, MG, Brasil \\ isabelladenadae@gmail.com
}

\begin{abstract}
RESUMO
O presente artigo busca analisar os padrões de viagem considerando-se, a partir da habitação, os deslocamentos para o trabalho e estabelecimentos educacionais. Busca-se analisar as distâncias percorridas, e os modais de transporte na cidade de Uberlândia, MG. Para tal, recorreu-se à aplicação de questionários, posterior inserção em banco de dados georreferenciado para cálculo das distâncias e uso de software estatístico para análise de dados. Os resultados demonstraram que a medida em que aumenta a renda familiar e o nível de escolaridade, maior é a escolha pelo automóvel individual. Os dados também evidenciam uma ampliação constante e generalizada dos transportes motorizados individuais por meio de aplicativos, principalmente em faixas etárias de 19 a 29 anos. O trabalho mostra ainda que carros ou motos o meio de transporte mais utilizado para as viagens ao trabalho e para as viagens à escola pelo gênero masculino. Para as viagens à escola pelo gênero feminino, os meios de transporte são mais diversificados e combinados entre si. A partir das análises desenvolvidas espera-se contribuir com as decisões de planejamento urbano e formulação de políticas públicas de transporte. Também espera-se contribuir para a mitigação dos impactos causados pelos deslocamentos diários, derivados das viagens para trabalho e educação.
\end{abstract}

Palavras-chave: Mobilidade Urbana. Modais de transporte. Comportamento de viagem. Trabalho. Escola.

\section{PATTERNS OF INTRAURBAN TRAVEL FOR WORK AND EDUCATIONAL ESTABLISHMENTS: EVIDENCE FROM THE CASE STUDY OF UBERLÂNDIA - MG}

\begin{abstract}
This article aims to analyze travel patterns considering, from housing, commuting to work and educational establishments. It seeks to find out the distances covered, and the means of transport in the city of Uberlândia, MG. For this, questionnaires were applied, later inserted in a georeferenced database to calculate distances and use statistical software for data analysis. The results showed that the greater the family income and education level, the greater the choice for the individual car. The data also shows a constant and widespread expansion of individual motorized transport through applications, mainly in the 19-29 age group. The work also shows that cars or motorcycles are the most used means of transport for work trips and trips to school by the male gender. For trips to school by the female gender, the means of transport are more diverse and combined. Based on the analyzes
\end{abstract}


developed, it is expected to contribute to urban planning decisions and the formulation of public transport policies. It is also expected to contribute to mitigating the impacts caused by daily commuting, derived from trips to work and education.

Keywords: Urban Mobility. Means of Transportation. Trip Behavior. Work. School.

\section{INTRODUÇÃO}

Extensa literatura tem demonstrado as relações do uso do solo urbano com os padrões de viagem. Dentre atividades com maior geração de viagens, destacam-se 0 trabalho e a educação. Diferentemente de outros usos terciários, cujas decisões de viagens podem ser flexibilizadas e, portanto, sujeitas a diversas variáveis, as viagens com destino ao trabalho e aos estabelecimentos educacionais têm como características uma certa rigidez nas decisões de deslocamentos, já que frequentemente demandam rotinas com horários mais rígidos. Além disso, nem sempre é possível conciliar a localização da moradia em proximidade com o local de trabalho. Além disso, conforme analisou Pero e Stefaneli (2015), aliado ao progressivo aumento das taxas de motorização no Brasil, houve um expressivo aumento no tempo de deslocamentos em especial nas viagens de casa ao trabalho.

Boa parte dos estudos, sobre os padrões de viagem, centram-se no caso das regiões metropolitanas, onde condições de uso do solo e mobilidade são bastante diversas das cidades médias, para as quais há carência de estudos. Com a constatação de que as cidades médias apresentam ainda um índice de congestionamentos abaixo dos apresentados nas grandes cidades, infere-se que há maior percentual de uso do automóvel e mesmo com maior frequência de viagens, materializada, por exemplo no hábito de almoçar em casa, notadamente mais frequente em cidades menores.

A partir dessas premissas, esse trabalho busca entender os padrões de viagem da moradia para o trabalho e educação analisando as distâncias percorridas e os modais de transporte na cidade de Uberlândia, MG. Para tal, recorreu-se à aplicação de questionários em meio eletrônico e presencial em campo, com posterior inserção em banco de dados georreferenciado para cálculo das distâncias e uso de software estatístico para sistematização de dados. A pesquisa investigou as motivações e características de viagens ao trabalho e para estabelecimentos educacionais a partir de um olhar específico sobre as cidades médias. Também destaca-se 0 desenvolvimento e adaptação de metodologia de análise computacional para propiciar a análise de maior número de variáveis.

\section{REVISÃO BIBLIOGRÁFICA}

Em meados do século $X X$ o Brasil inicia uma expansão urbana acelerada, inspirada no crescimento econômico-industrial, associado ao aumento da população urbana, possível pelo êxodo rural. Essas duas condições, aliadas ao processo de especulação imobiliária, protagonizado pelo capital incorporador, contribuiu para a ocupação dispersa da cidade, tornando os sistemas de transporte importante variável na qualidade de vida das pessoas. A expansão urbana, formando as periferias, desprovidas de serviços e equipamentos públicos, é resultado da ausência de articulação/integração entre as políticas de planejamento e de mobilidade (ALVES, FERREIRA, 2014).

A urbanização centrada no automóvel foi referendada pelas políticas de zoneamento, uso do solo e de mobilidade, ao longo dos séculos XX e XXI, de maneira a privilegiar as demandas que vinham junto com o uso do automóvel, em detrimento do transporte coletivo e, ainda menos outros modos de transporte não motorizados. O espaço do automóvel reflete a força dos grupos sociais de média e alta renda, que por meio desse espaço urbano reproduziram as relações econômicas, sociais e políticas durante a expansão urbana (VASCONCELLOS, 2017).

Sendo assim, o espaço da rua se distribui de forma desigual entre os diversos atores (pedestres, ciclistas, veículos particulares, ônibus e outros) e historicamente os projetos viários privilegiaram os veículos particulares, na tentativa de acomodar o volume crescente de veículos motorizados. Além de garantir a fluidez do tráfego com a permissão de altas velocidades na área urbana (ALVES, FERREIRA, 2014). 
Um sentido mais amplo do termo mobilidade urbana foi definido na Política Nacional de Mobilidade Urbana (BRASIL, 2012) como a "condição em que se realizam os deslocamentos de pessoas e cargas no espaço urbano". A partir daí se estabeleceram diretrizes para a mobilidade urbana no país buscando maior integração da política de desenvolvimento urbano com as políticas de habitação, saneamento básico, planejamento e gestão do uso do solo. Ao menos no papel, se estabeleceu a priorização dos modos de transporte não motorizados sobre os motorizados e dos serviços de transporte público coletivo sobre o transporte individual motorizado. Essa integração busca a redução dos impactos negativos na qualidade de vida das pessoas na cidade, como a fragmentação do espaço urbano e a segregação socioespacial, reduzir congestionamentos, horas desperdiçadas no deslocamento casa-trabalho e casa-escola, poluição do ar, acidentes de trânsito, o aumento das doenças não transmissíveis (diabetes, obesidade, doenças respiratórias).

Embora com bons propósitos, ainda não se pode observar na prática os resultados da Política Nacional de Mobilidade Urbana. Continuam as cidades com um sistema de transporte que favorece a fragmentação do espaço urbano, prioriza gastos com infraestrutura viária e posteriormente leva ao aumento da pressão no sistema de transporte público, para atender a demanda das viagens, principalmente casa-trabalho e casa-escola, que são as principais atividades necessárias do cotidiano, num ciclo perverso (BOARETO, 2003). Observa-se que o planejamento quando há, não se dá de maneira coordenada. Assim, as linhas de transporte acompanham a expansão das áreas urbanizadas das cidades, até as periferias, nem sempre acompanhadas de oferta de empregos e serviços públicos, resultando em alta demanda de viagens das pessoas para outras regiões da cidade.

Segundo Villaça (2001), o trabalhador segue o capital em busca de emprego, até em outras cidades e regiões. Porém, depois que se instala em determinada cidade, ele não muda de casa toda vez que muda de emprego, já que têm suas relações e condições de consumo já otimizadas. Portanto, ele necessita de meios que assegurem seu deslocamento diário, como o transporte público e as vias de ligação entre os bairros.

Cervero e Wu (1998) criticam a dificuldade dos trabalhadores em acompanhar as mudanças do local de trabalho, pois seus membros familiares têm outras atividades, além de seus percursos e tempos já programados. Pode-se considerar também os custos de morar próximo à oferta de emprego, já que o preço da terra costuma ser elevado. Desse modo, os indivíduos de baixa renda ficam condicionados a moradias longes, e precisam gastar tempo e dinheiro com transporte.

Para Smolka (1987 apud SANTOS, 2016) a moradia é uma mercadoria que agrega valor com as particularidades dos locais onde se encontra, como presença de meios de socialização, de lazer, acessibilidade, proximidade com comércios, escolas, hospitais, dentre outros. Essas particularidades passam a ser atributos vinculados a moradia e, portanto, agregam valor em sua negociação.

Para análise das distâncias percorridas por um indivíduo durante o dia, é importante citar os estudos que realizam uma comparação entre o mercado formal e o informal, pois muitos trabalhadores escolhem o local de moradia a partir da localização do trabalho. Além disso, o emprego informal costuma gerar residências próximas, enquanto a preocupação com as regiões de residência e trabalho não é tão importante para o trabalhador formal (LIMA NETO et. al., 2016). Ou seja, ele não se importa de percorrer grandes distâncias no cotidiano nem de ter custos extras com mobilidade, o que impacta diretamente na escolha do meio de transporte e no sistema viário da cidade. A disputa pelo tempo de deslocamento se tornou uma ferramenta da classe dominante, que compra não só o espaço, mas também as distâncias, o que, consequentemente, vira valor de uso do espaço (VILLAÇA, 2001).

O modelo logit multinomial, proposto por Erwing et. al. (2004), tem o automóvel como base das pesquisas e analisa algumas variáveis: renda familiar, número de automóveis por domicílio, possuir ou não carteira de motorista, tempo gasto nas viagens a pé e de bicicleta, qualidade das calçadas no percurso e o índice médio de acessibilidade - não foram encontrados estudos no Brasil sobre essa variável específica, os autores analisam a realidade estadunidense. Assim, a situação socioeconômica mostra como os habitantes decidem os meios de locomoção usados nas tarefas do dia a dia, como a ida às instituições de ensino e ao trabalho. 
No caso das viagens com origem na moradia e destino na escola ou instituição de ensino, é possível analisar o fluxo de pessoas e veículos por meio de algumas variáveis explicativas, como o número de alunos, a quantidade de funcionários e a área do local, segundo o Instituto de Engenharia de Transportes (ITE, 2008). Outro autor ainda faz distinção entre as instituições de caráter público e privado, e sua análise se restringe aos deslocamentos por automóvel, ônibus e a pé (BERTAZZO, 2008). Herz et. al. $(2007,2009)$, diferente dos outros, inclui a distância entre a instituição de ensino e o centro da cidade, o que se aproxima do presente artigo. É importante salientar que, em várias destas análises, o número de alunos é o fator independente na pesquisa (ERWING et. al., 2004; BERTAZZO, 2008; HERZ et. al., 2007, 2009).

As instituições de ensino e escolas, por atrair um grande contingente de pessoas e, consequentemente, de viagens, podem se tornar Polos Geradores de Viagem (PGV). Caso isso aconteça, há impactos no sistema viário da região, que pode ocasionar aumento no tempo de percurso durante determinados horários, visto que a frequência com que as pessoas se deslocam até esses locais é considerável (JACQUES et. al., 2010).

$\mathrm{Na}$ integração dos sistemas de informação geográfica (SIG) com o planejamento de transportes, já foi desenvolvida em vários estudos. Essa ferramenta é importante porque permite várias análises propiciando otimizar o transporte público, avaliar o crescimento de determinadas regiões da cidade, definir locais estratégicos para escolas e outros usos coordenados do solo (RAIA JR., 2000).

\section{METODOLOGIA}

A fim de entender o comportamento de viagem e o cotidiano dos moradores de Uberlândia, foi aplicado um questionário do tipo origem/destino, que também continha perguntas sobre o hábito de compras e informações socioeconômicas dos entrevistados. A coleta de dados ocorreu de forma online e em visitas de campo a equipamentos coletivos espalhados pela cidade e com grande fluxo diário, como postos de saúde, hipermercados e Unidades de Atendimento Integrado (UAl), para obter respostas abrangentes de todas as regiões.

Uberlândia está no Estado de Minas Gerais, na Mesorregião do Triângulo Mineiro e Alto Paranaíba, com área urbana de $219 \mathrm{Km}^{2}$ e população total em 2010, pelo Censo - Instituto Brasileiro de Geografia e Estatística - IBGE, de 604.013 habitantes (UBERLÂNDIA, 2019).

O questionário eletrônico utilizou-se da plataforma 'Online Pesquisa'. Com isso, gerou-se uma variedade de diferentes modelos de perguntas, moldando o questionário às necessidades da avaliação. Durante o período em que a pesquisa foi realizada, foi possível ter uma pré-visualização exata de perguntas individuais, bem como de todo o questionário.

A pesquisa, realizada no período de 3 meses, coletou dados sobre a frequência com que as pessoas se deslocam até determinados pontos: trabalho, escola ou instituição de ensino, considerando-se o meio de transporte utilizado nessas viagens, incluindo levar filhos ou outras pessoas: ônibus, carro ou moto, aplicativos de transporte, bicicleta, a pé ou nenhum; da moradia aos destinos. Para preservação da segurança e privacidade dos entrevistados, foram considerados como pontos de origem, apenas o CEP da moradia, sem a identificação de número.

Partindo-se do pressuposto de que as viagens diárias ocorrem a partir do domicílio, foi utilizada a pesquisa Origem Destino (OD), com o método da "Linha de Contorno", por meio do levantamento de dados dos indivíduos que se deslocam pela região de investigação. Assim, a amostragem, não probabilística, estabeleceu uma quota de habitantes para a pesquisa, independentemente do local da entrevista e da forma de preenchimento - online ou em campo. O tipo de pesquisa escolhido se deu pelo baixo custo e pela fácil execução, além dos dados coletados serem satisfatórios para as análises desejadas no estudo.

Pesquisa Origem Destino é a denominação que se dá para as pesquisas de tráfego realizadas no próprio local objeto de planejamento, podendo ser realizadas de diversos modos, mas sempre visando coletar dados que possibilitem o planejamento de sistemas de transportes. Os tipos mais utilizados são as pesquisas nas vias e as domiciliares, a primeira sendo usada tanto para planos em 
zonas urbanas quantos em zonas rurais, enquanto a segunda é mais utilizada em planos de transportes urbanos (MELO, 1975 APUD RAIA JR., 2000).

A técnica de pesquisa de entrevista domiciliar tem sido a maior fonte de obtenção de dados para estudos de transportes nas últimas décadas (RICHARDSON ET AL., 1995). Os resultados da pesquisa domiciliar OD delimitam a distribuição territorial da população e dos locais de interesse das viagens. É essa característica de espacialização das informações na área urbana que torna a pesquisa diferenciada das demais pesquisas do gênero. Seus resultados são sempre de grande valia não só para estudos de transportes, como também para áreas afins. (RICHARDSON ET AL., 1995).

A pesquisa Origem Destino é normalmente realizada com o objetivo de conhecer não só os pontos iniciais e finais das viagens, como também os horários, comprimentos, tempos de viagens, dados socioeconômicos dos viajantes, etc. A pesquisa é feita mediante o preenchimento de um questionário, por meio de uma entrevista que o pesquisador faz com as diversas pessoas.

As respostas resultantes do trabalho foram tabuladas na plataforma Qlik View. Esta plataforma é um software de Business Intelligence, ou seja, é possível organizar, analisar, compartilhar e monitorar dados, integrando-os em uma única plataforma. Além disso, estes dados podem ser importados em formatos como html, xml, word, txt e qualquer base de dados através de um conector ODBC. QlikView é uma plataforma para construção de aplicações analíticas dentro do conceito de self-service BI e Data Discovery. Como self-service BI entende-se que o QlikView possibilita a usuários avançados construírem suas próprias aplicações analíticas, que depois são validadas e homologadas com a área de TI dentro do processo de governança de BI. Depois de homologada, a aplicação é publicada no servidor QlikView para visualização pelos demais usuários da organização. Como uma ferramenta Data Discovery, ela possibilita aos usuários navegarem na aplicação desenvolvida e explorar os dados através dos painéis de forma livre, sem caminhos predefinidos. Durante o desenvolvimento da aplicação, ela também possibilita descobertas de dados e relações que muitas vezes estão ocultas em relatórios estáticos.

O QlikView único é o modelo de dados associativo "in-memory". Esta tecnologia patenteada pela Qlik faz com que as análises agreguem os dados e se construam hierarquias de dimensões em tempo de execução, sem pré-processamento. As associações entre tabelas são tratadas como se fossem um full-outer join entre tabelas no modelo relacional com SQL, permitindo que seja possível avaliar o que está associado e o que não está associado ao contexto de filtros aplicados pelo usuário enquanto ele analisa os dados. Com isso, as 182 respostas foram tabuladas a partir do tratamento estatístico dos dados coletados na pesquisa, com a geração de gráficos e tabelas para análise dos resultados obtidos, de maneira limpa e didática.

Após essa etapa, as informações foram tratadas em um sistema de informação geográfica (SIG), utilizando-se o software Quantum GIS (QGis), um meio de análise, criação, edição e visualização de dados georreferenciados da cidade, para entender as distâncias e fluxos entre o trabalho e a escola do ponto de partida cotidiano, a residência. A vantagem do SIG em relação a outras técnicas tradicionais é a agilidade, já que o sistema automatizado oferece novas formas de se representar graficamente e analisar os dados gerados (RAIA JR., 2014). Tudo isso por meio da teoria dos campos vetoriais de interação e pelas dissimilaridades direcionais, que identificaram as áreas com maior concentração de fluxos de um determinado ponto (FERREIRA, 2014). Assim, a técnica de interpolação pelo algoritmo do inverso do quadrado das distâncias (IQD) - interpolação univariada por média ponderada, parte do ponto de interesse $x$, a partir do qual tomam-se as medidas $x$, onde $i$ varia de $1 \mathrm{a}$. O valor desconhecido é representado por $z(\mathbf{x})$ e o conhecido por $z_{i}$. Cada ponto recebe um peso $w_{i}$, avaliado com base em $d_{i}$ (distância de $\mathbf{x}_{i}$ para $\mathbf{x}$ (LONGLEY ET AL, 2013, P. 375). Então, a média ponderada é o resultado de:

$$
Z(\mathbf{x})=\sum w_{i} z_{i} / \sum w_{i}
$$

O peso neste caso é atribuído pelo inverso do quadrado da distância, ou seja:

$$
w_{i}=1 / d_{l}^{2}
$$


Este método de inferência espacial faz parte dos modelos determinísticos de estimação, os quais "têm por base critérios puramente geométricos em que as distâncias são euclidianas e não fornecem medidas de incerteza" (YAMAMOTO; LANDIM, 2013, p. 22).

O algoritmo IQD gera um arquivo raster (.tif), em que os valores dos pixels simbolizam o valor do atributo selecionado para o cálculo, que no caso do estudo é a frequência absoluta do fluxo de veículos/semana dos bairros de destino, saindo dos bairros de origem. Desse modo, foram definidas classes conforme a frequência absoluta para área de influência, indo de "muito baixa" até "muito alta", pela concentração do fluxo de veículos em cada região. Além disso, as técnicas de ponderação de matrizes a partir de modelos gravitacionais foram aplicadas a fim de entender a interação espacial de cada um dos pontos determinados com aqueles presentes na tabela de atributos (FERREIRA, 2014). De acordo com Câmara et. al. (2001, p. 06):

\begin{abstract}
"As redes são representadas através de matrizes de interação espacial, nas quais cada localidade onde se originam e destinam fluxos é representada por um ponto no espaço e os fluxos entre estas entidades são indicados como entradas numa matriz origem-destino".
\end{abstract}

Por meio dos dados de fluxo levantados na Pesquisa Origem Destino (OD), foi provável estabelecer graus de interação espacial I entre os nós de uma determinada rede (FERREIRA, 2014, p. 180) para construir o grafo, derivado de distintos pontos da cidade até os pontos finais de destino.

Segundo Ferreira (2014, p. 166), o grafo é composto por diversos elementos, dentre eles a conexão ou link, o nó ou vértice, região nodal, e rede. A conexão é representada graficamente pelo objetivo linha; o nó é um objeto simbolizado pelo ponto; a região nodal é demarcada por um polígono; e a rede integra todos os elementos e dá forma ao arranjo espacial. Por este motivo, o grafo pode ser aplicado em SIG, como o QGis, que se estrutura em dados vetoriais georreferenciados e se localiza no âmbito da rede (FERREIRA, 2014, p. 167).

No que se refere aos questionários aplicados, cabe salientar que a pesquisa se centrou em moradores da cidade de Uberlândia. As visitas a campo realizaram-se no período da tarde, pelos próprios pesquisadores, um dia em cada local visitado - UAl, postos de saúde e hipermercados. Enquanto isso, os questionários online ficaram disponíveis por dois meses, e foram divulgados principalmente por meio de redes sociais. Com base nas informações obtidas e posterior tratamento das mesmas, foi possível observar os impactos causados pelo fluxo de pessoas de casa para o trabalho e/ou escola na malha urbana de Uberlândia, como poderá ser visto abaixo.

\title{
RESULTADOS
}

Por meio das respostas obtidas diante da amostragem piloto, gerou-se dados tabulados pelo software QlikView onde, das 182 resoluções, 68,3\% corresponde ao público feminino; 30,5\% ao masculino e $1,2 \%$ outro. Quanto a faixa etária, o questionário atingiu $0 \%$ dos que apresentariam ter de 0 a 18 anos; seguido por pessoas entre 19 a 29 anos com 57,3\%; de 30 a 50 anos, com 31,7\% e acima de 50 anos, $11 \%$. Mais adiante, os participantes descrevem na pergunta três (3) do questionário, qual a classificação de seu grupo familiar, totalizando em $15,9 \%$ sozinho; $11 \%$ monoparental; $57,3 \%$ casal com filhos; $4,9 \%$ casal sem filhos; $8,5 \%$ coabitação sem vínculo afetivo e $2,4 \%$ outros. No quesito renda mensal, $8,5 \%$ apresenta renda até $R \$ 1.000 ; 17,1 \%$ de $R \$ 1.000$ a $R \$ 3.000 ; 18,3 \%$ de $R \$ 3.000$ a $R \$ 5.000 ; 28 \%$ de $R \$ 5.000$ a $R \$ 10.000$ e $28 \%$ acima de $R \$ 10.000$. Sob a mesma ótica analisa-se que, diante do nível de escolaridade dos participantes, $0 \%$ apresentam apenas ensino fundamental; 18,3\% ensino médio; $57,3 \%$ ensino superior e $24,4 \%$ pós-graduação.

Assim, após a análise pessoal dos mesmos, a pesquisa avança para o estudo aplicado em 6 tópicos: trabalho; escola; shopping centers; vestuário; supermercado e mercearia, a fim de aplicar os estudos abordados acima. Neste artigo, trataremos dos dois primeiros, trabalho e escola. Ao que se refere ao trabalho, $57,32 \%$ dos entrevistados vão cinco vezes na semana; $9,76 \%$, três vezes na semana; $2,44 \%$, uma vez na semana; $1,22 \%$, uma vez ao mês; $2,44 \%$, esporadicamente e $26,83 \%$, não trabalham. 
Figura 1 - Uberlândia (MG): Viagens para trabalho: frequência e meios de transporte, 2019.
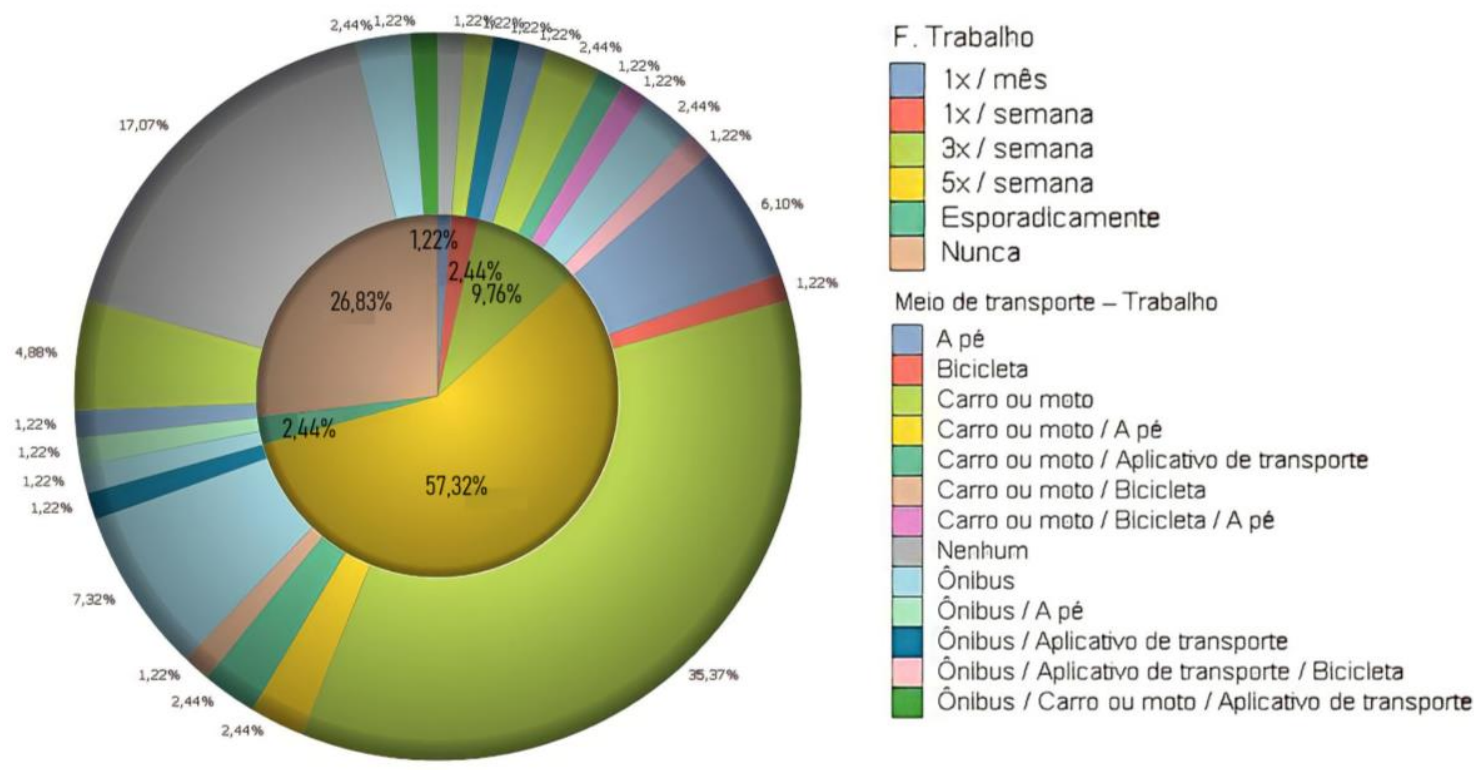

Fonte - Autores, 2019

De acordo com a Figura 1, carros ou motos são os meios de transporte mais utilizados, com 48,79\%; seguido por ônibus $(17,08 \%)$; a pé $(13,42 \%)$; aplicativo de transporte $(6,10 \%)$; bicicleta $(4,88 \%)$; e nenhum (17,07\%). É possível notar que, dentre as respostas de 'nenhum', ou seja, em que as pessoas não realizam a atividade analisada, alguns entrevistados responderam o meio de transporte utilizado. Assim, pode significar que eles utilizariam o meio, caso frequentassem o local.

Figura 2 - Uberlândia (MG): Viagens para trabalho: por gênero - feminino, 2019.
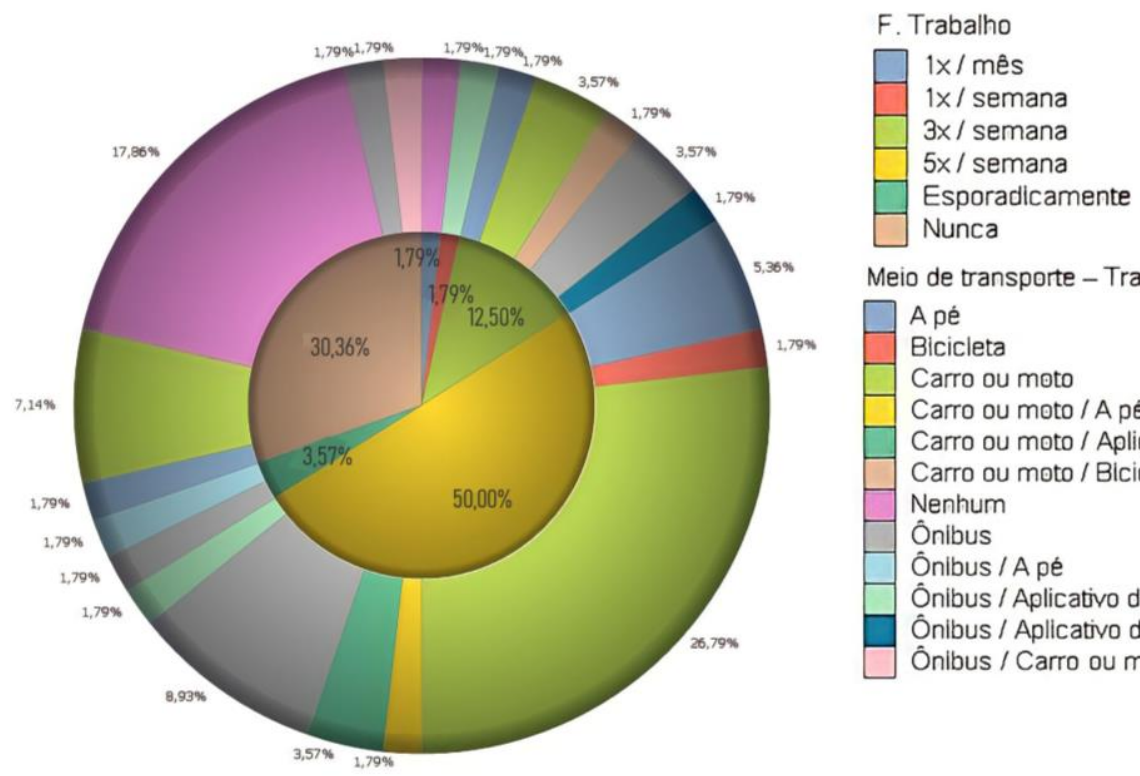

Meio de transporte - Trabalho

\section{A pé
Bicicleta}

Carro ou moto

Carro ou moto / A pé

Carro ou moto / Aplicativo de transporte

Carro ou moto / Bicicleta / A pé

Nenhum

Ônibus

Ônibus / A pé

Ônibus / Aplicativo de transporte

Ônibus / Aplicativo de transporte / Bicicleta

Ônibus / Carro ou moto / Aplicativo de transporte

Fonte - Autores, 2019.

Pelas Figuras 2 e 3, têm-se que tanto o gênero feminino quanto o masculino vão ao trabalho com predominância de cinco vezes na semana, sendo que o segundo tem porcentagem ainda maior (76,00\%, contra $50,00 \%$ do primeiro). Do gênero feminino, também vão ao trabalho três vezes na semana (12,50\%), esporadicamente (3,57\%) e uma vez por mês e uma vez na semana $(1,79 \%$ cada). Já do masculino, frequentam uma vez na semana e três vezes na semana a mesma porcentagem, 
4,00\%. Quanto aos que não trabalham, correspondem a 30,36\% das mulheres e $16 \%$ dos homens. Em relação ao meio de transporte, as entrevistadas usam meios mais diversificados, com a escolha maior entre carro ou moto $(46,44 \%)$, ônibus $(25,03 \%)$, e a pé $(14,31 \%)$. Os entrevistados do gênero masculino escolhem predominantemente o carro ou moto $(72,00 \%)$, enquanto ônibus ou a pé tem taxas iguais $(8,00 \%)$.

Figura 3 - Uberlândia (MG): Viagens para trabalho: por gênero - masculino, 2019.
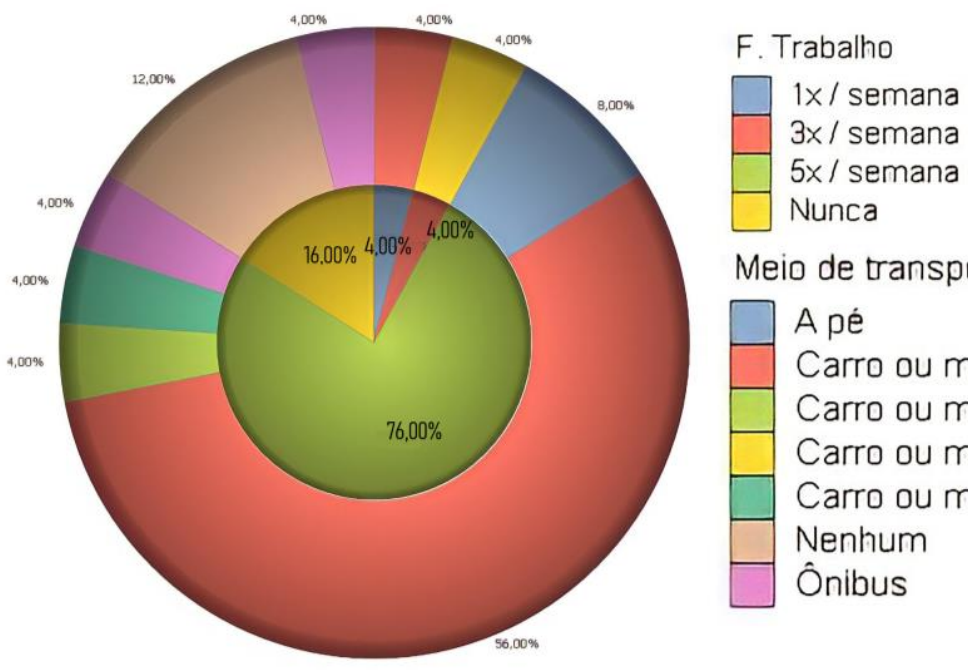

Meio de transporte - Trabalho

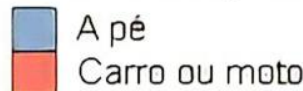

Carro ou moto / A pé

Carro ou moto / Aplicativo de transporte

Carro ou moto / Bicicleta

Nenhum

Ônibus

Fonte - Autores, 2019.

A partir da faixa etária (Figuras 4, 5 e 6), apreende-se que, quanto menor a idade, mais as pessoas tendem a usar diferentes meios de transporte para os seus deslocamentos de trabalho, como aplicativos de transporte, ônibus e a pé. Entre os 19 e 29 anos, 34,05\% utilizam carro ou moto combinado ou não com outro meio, enquanto na faixa de 30 a 50 anos esse número sobe para $73,01 \%$. Acima de 50 anos, vai para $77,77 \%$, no cenário em que muitas pessoas nem trabalham mais $(33,33 \%)$, e o restante utiliza ônibus $(11,11 \%)$. De 30 anos para cima, as viagens a pé são escassas, totalizando $11,55 \%$, ou seja, os mais velhos possuem menos facilidade de se locomover pelo espaço urbano.

Figura 4 - Uberlândia (MG): Viagens para trabalho: por faixa etária - 19 a 29 anos, 2019.

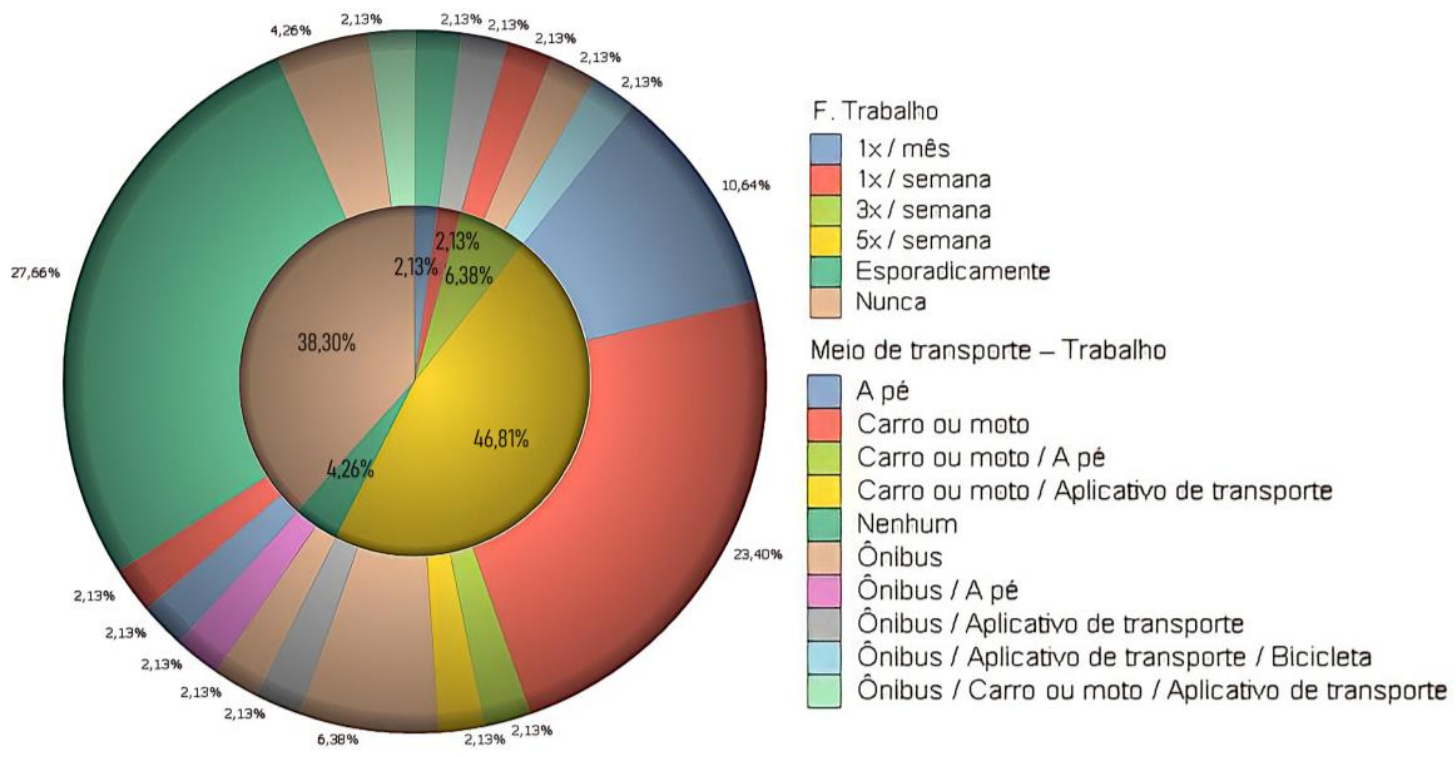

Fonte - Autores, 2019.

$\begin{array}{lllll}\text { Caminhos de Geografia } \quad \text { Uberlândia-MG } & \text { v. 21, n. } 78 & \text { Dez/2020 } & \text { p. 303-324 Página } 310\end{array}$


Figura 5 - Uberlândia (MG): Viagens para trabalho: por faixa etária - 30 a 50 anos, 2019.

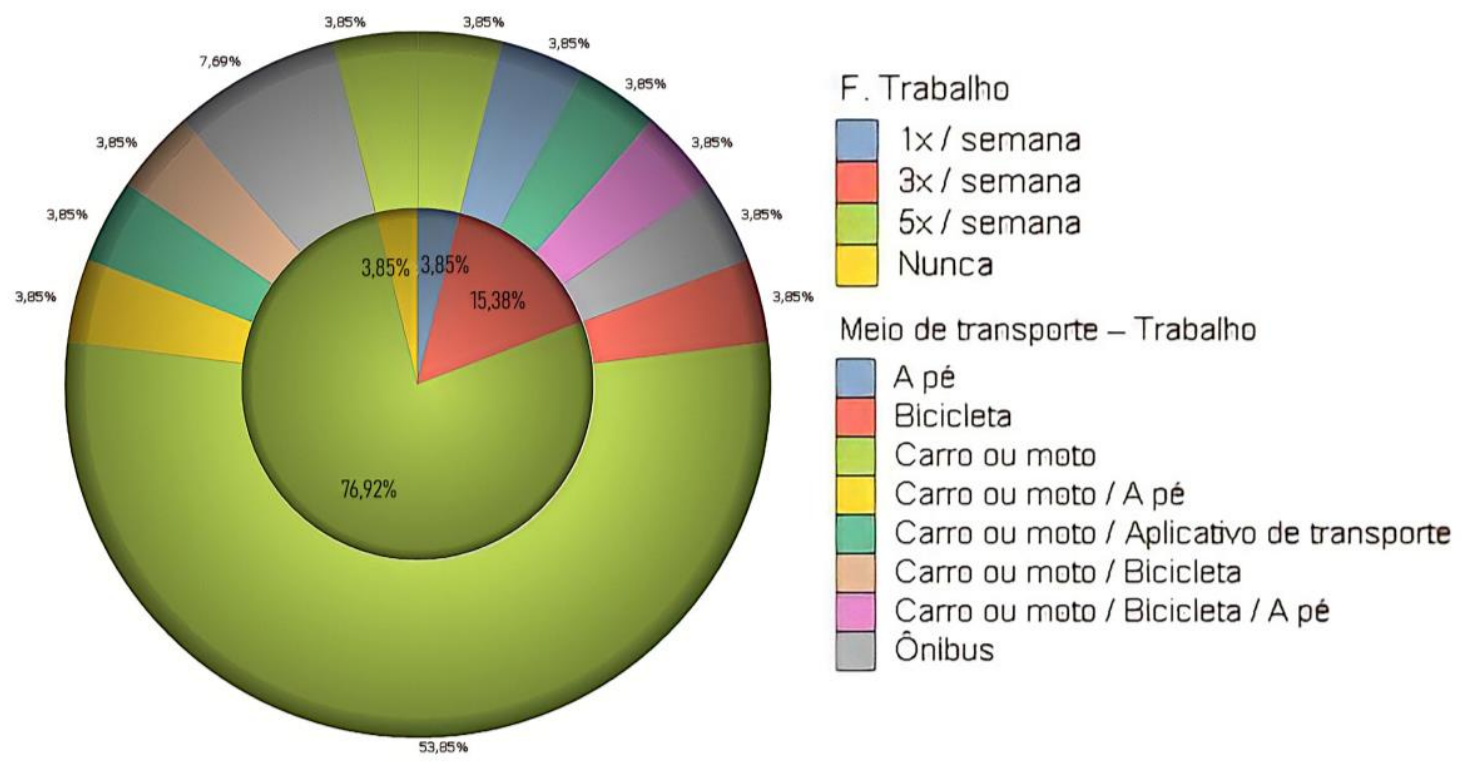

Fonte - Autores, 2019.

Figura 6 - Uberlândia (MG): Viagens para trabalho: por faixa etária - acima de 50 anos, 2019.

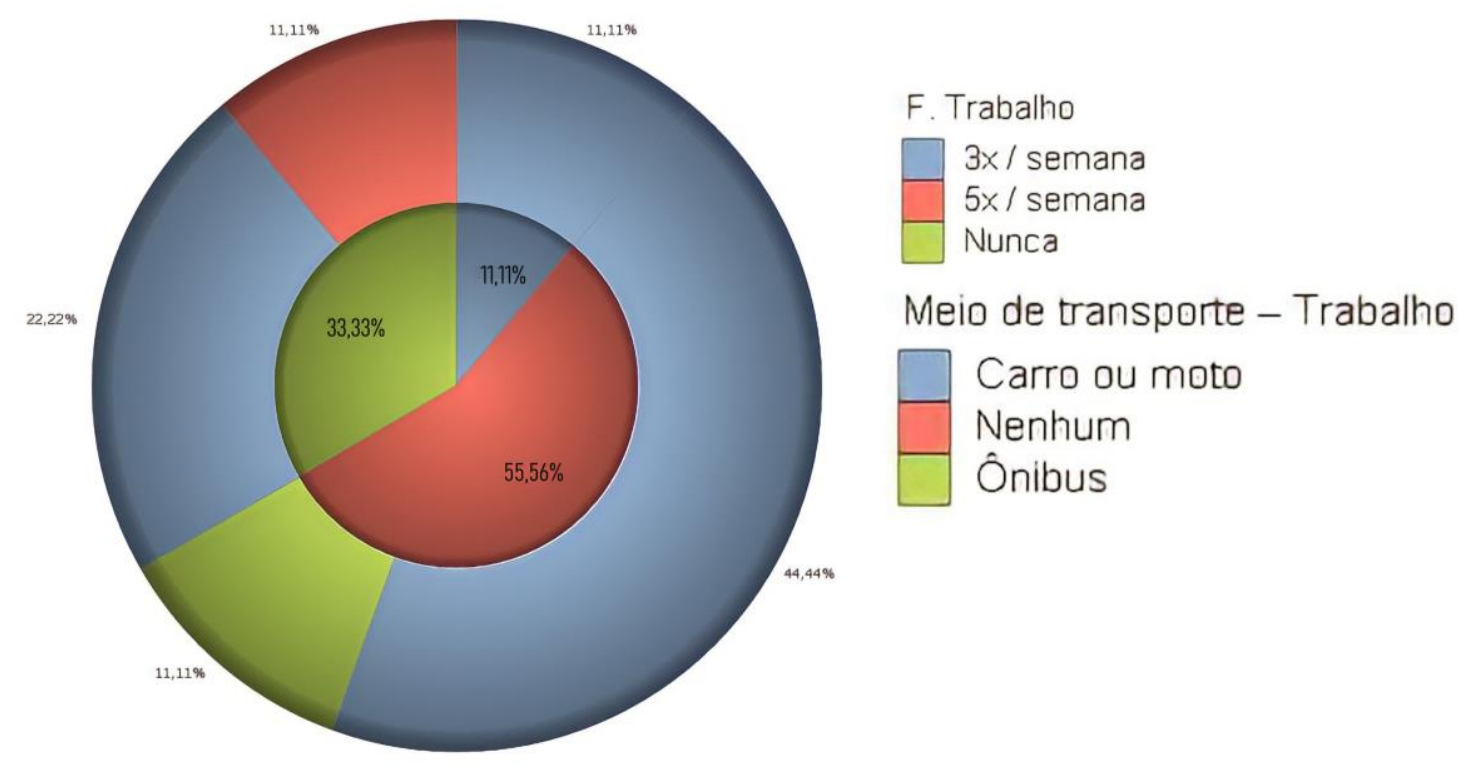

Fonte - Autores, 2019

Ao analisar os gráficos de viagens ao trabalho por meio da renda familiar (Figuras 7, 8, 9, 10 e 11) de cada entrevistado, é notório o maior uso do transporte público pelas pessoas de baixa renda. Dos entrevistados com renda de até $R \$ 1.000,00$ foram observadas as mesmas porcentagens tanto para carro ou moto, ônibus e a pé $(28,58 \%)$. De $R \$ 1.000,00$ a $R \$ 3.000,00$ a escolha pelo ônibus é de $28,57 \%$, enquanto de $R \$ 3.000,00$ a $R \$ 5.000,00$ desce para $20,01 \%$, de $R \$ 5.000,00$ a $R \$ 10.000,00$ vai para $21,74 \%$, porém combinado com outros meios de transporte. Por fim, acima de $R \$ 10.000,0$ a frequência é nula, o que mostra que a renda está atrelada ao poder aquisitivo e à compra do automóvel próprio - $69,58 \%$ vão de carro ou moto. Quanto à frequência, varia muito entre as rendas,

$\begin{array}{lllll}\text { Caminhos de Geografia } \quad \text { Uberlândia-MG } & \text { v. 21, n. } 78 & \text { Dez/2020 } & \text { p. 303-324 Página } 311\end{array}$


com maior discrepância entre as rendas de até $R \$ 1.000,00$ e de $R \$ 5.000,00$ a $R \$ 10.000,00$, indo de $28,57 \%$ a $73,91 \%$, dos que trabalham cinco vezes na semana, e de $71,43 \%$ a $17,39 \%$ dos que não trabalham, na ordem em que aparecem.

Figura 7 - Uberlândia (MG): Viagens para trabalho: por renda até $\mathrm{R} \$ 1.000,00,2019$.

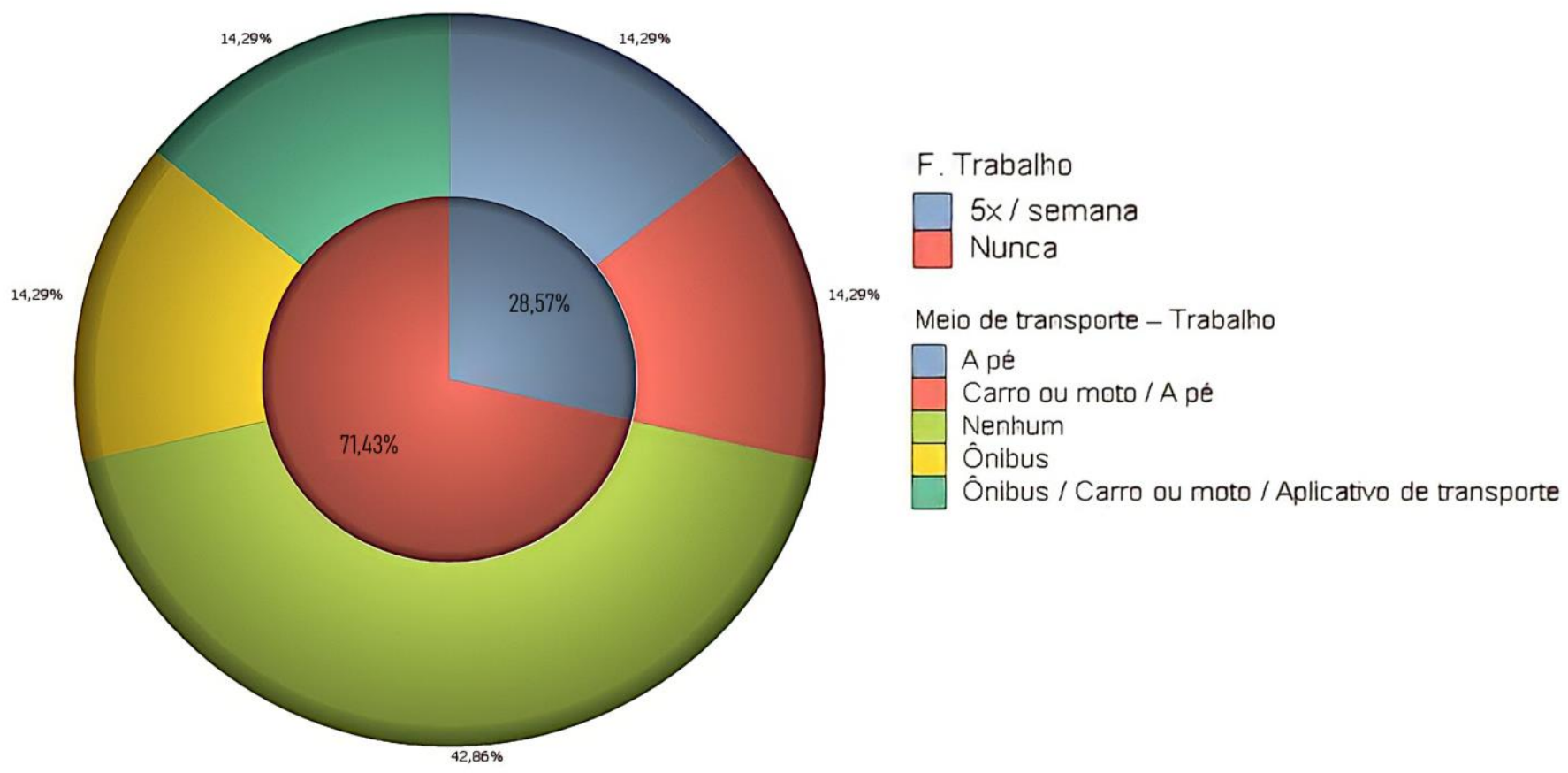

Fonte - Autores, 2019.

Figura 8 - Uberlândia (MG): Viagens para trabalho: por renda de $R \$ 1.000,00$ a $R \$ 3.000,00,2019$.

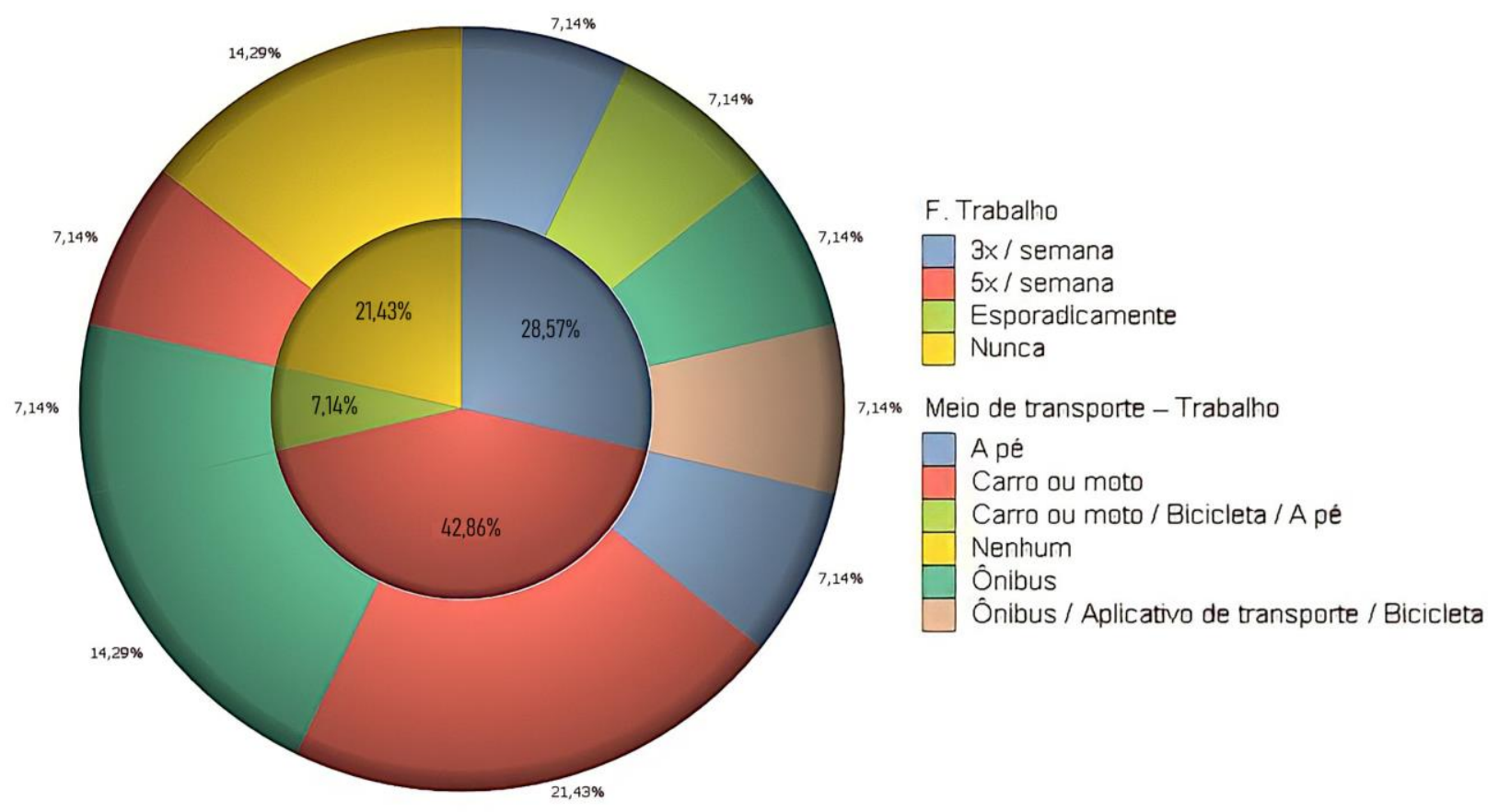

Fonte - Autores, 2019.

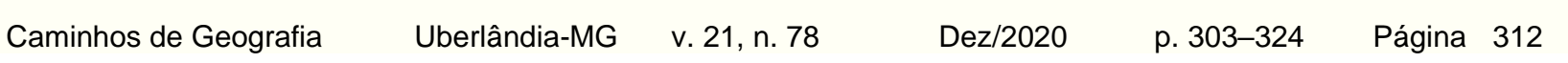


Figura 9 - Uberlândia (MG): Viagens para trabalho: por renda de $R \$ 3.000,00$ a $R \$ 5.000,00,2019$.

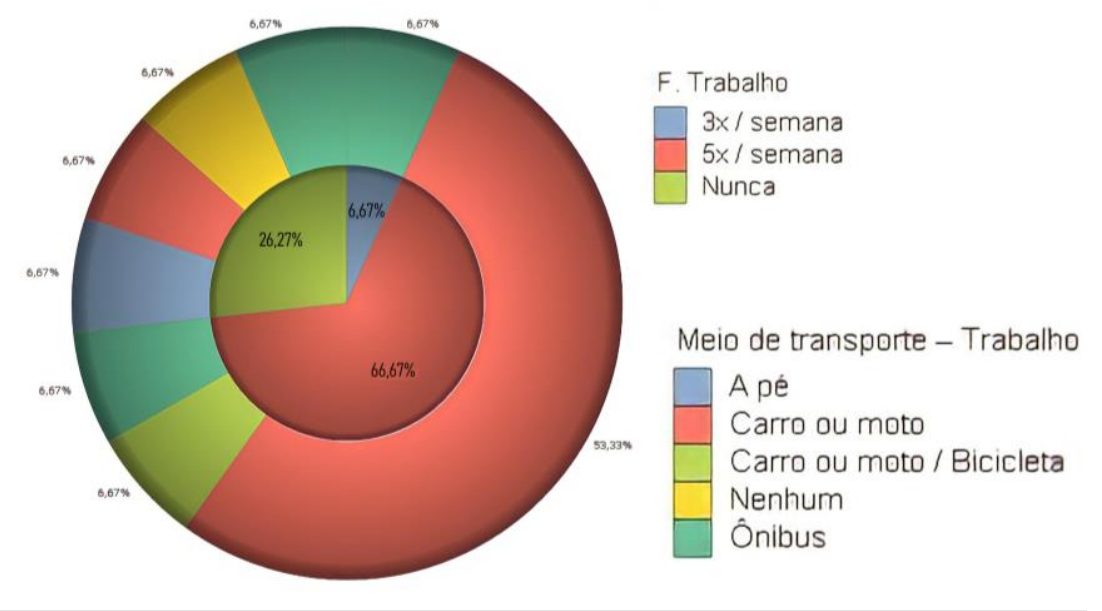

Fonte - Autores, 2019.

Figura 10 - Uberlândia (MG): Viagens para trabalho: por renda de $\mathrm{R} \$ 5.000,00$ a $\mathrm{R} \$ 10.000,00,2019$.
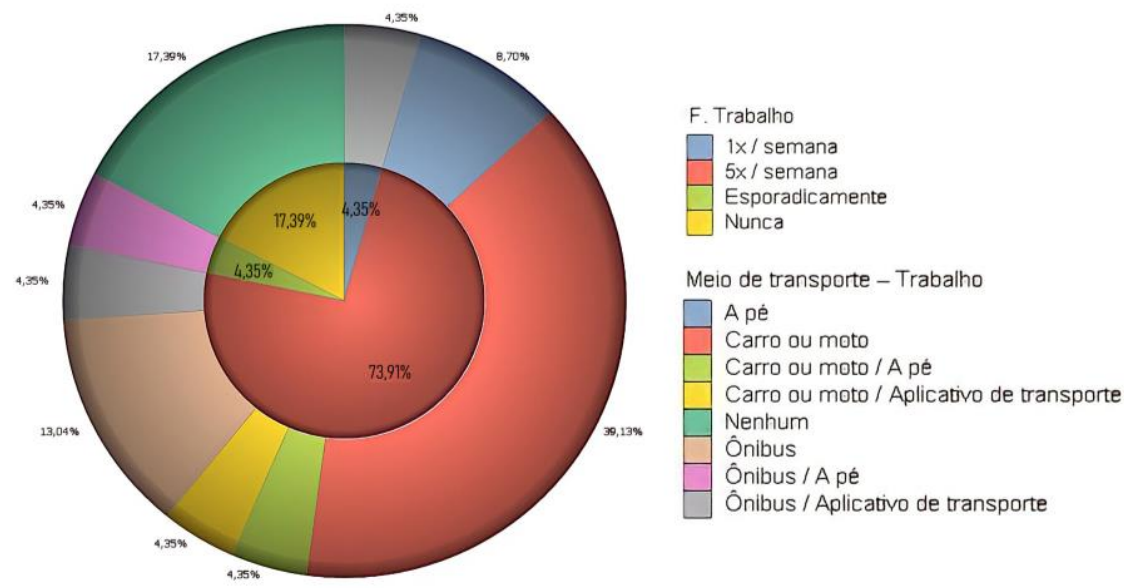

Fonte - Autores, 2019.

Figura 11 - Uberlândia (MG): Viagens para trabalho: por renda acima de $\mathrm{R} \$ 10.000,00,2019$.

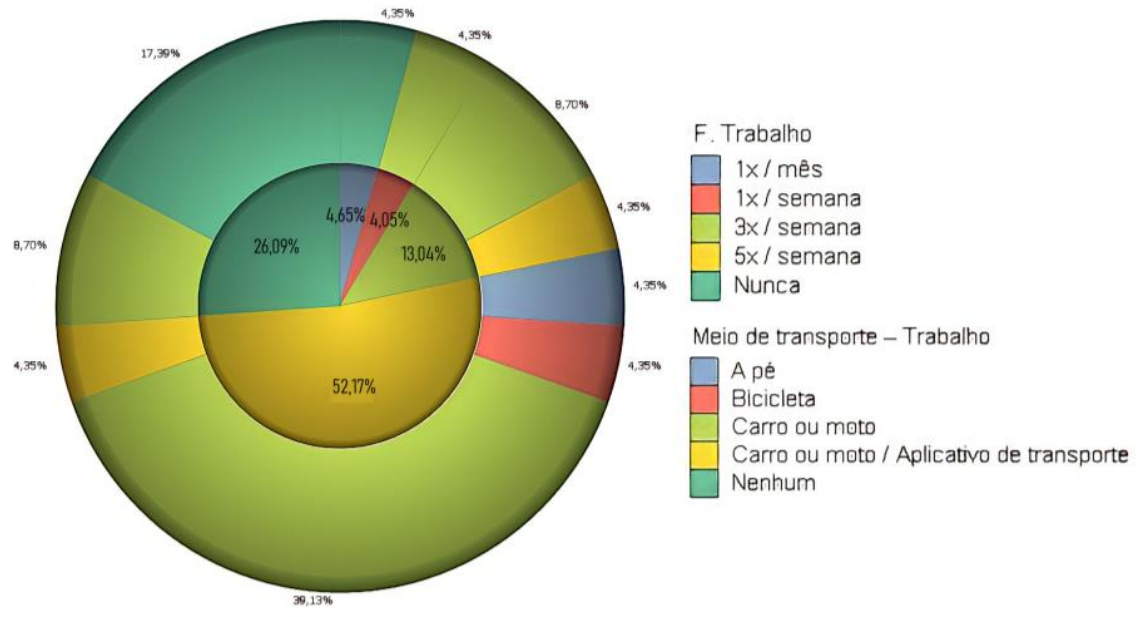

Fonte - Autores, 2019 
Outra análise possível ainda dentro do tema trabalho é a escolaridade (Figuras 12, 13 e 14) em que, quanto maior o nível de escolaridade, maior a renda familiar e menor o índice de pessoas que não trabalham. Das pessoas com ensino médio, 40,00\% trabalham cinco vezes na semana e $40,00 \%$ não trabalham; com ensino superior, $57,45 \%$ trabalham cinco vezes na semana e $29,79 \%$ não trabalham; e com pós-graduação, $70,00 \%$ trabalham cinco vezes na semana e 10,00\% nunca. Apesar do carro ou moto ser o principal meio de transporte para todos os níveis de escolaridade, é possível identificar uma grande variedade e diferentes combinações no uso dos transportes, principalmente nos entrevistados com nível superior, além do uso do ônibus ser relevante para os indivíduos que concluíram o ensino médio.

Figura 12 - Uberlândia (MG): Viagens para trabalho: por escolaridade - Ensino Médio, 2019.

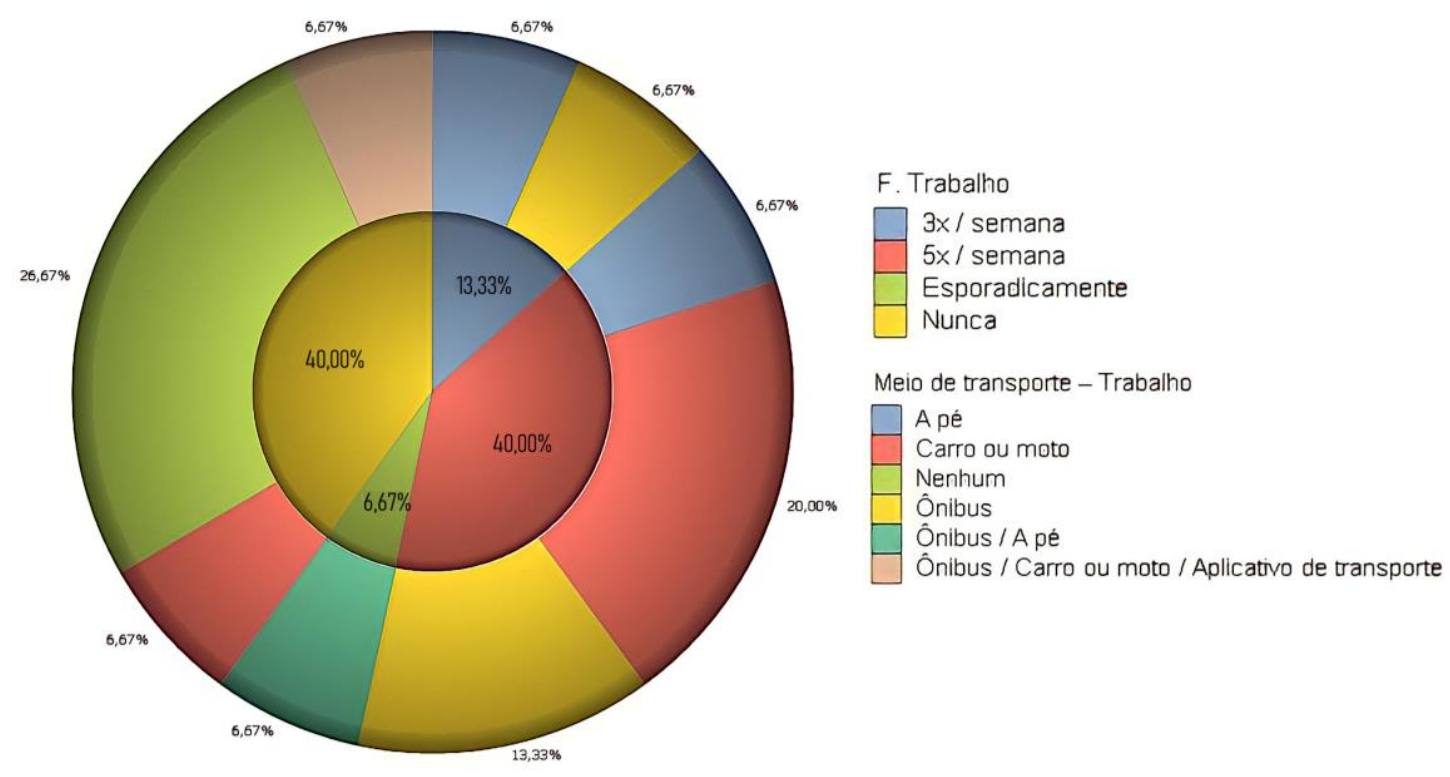

Fonte - Autores, 2019

Figura 13 - Uberlândia (MG): Viagens para trabalho: por escolaridade - Ensino Superior, 2019.
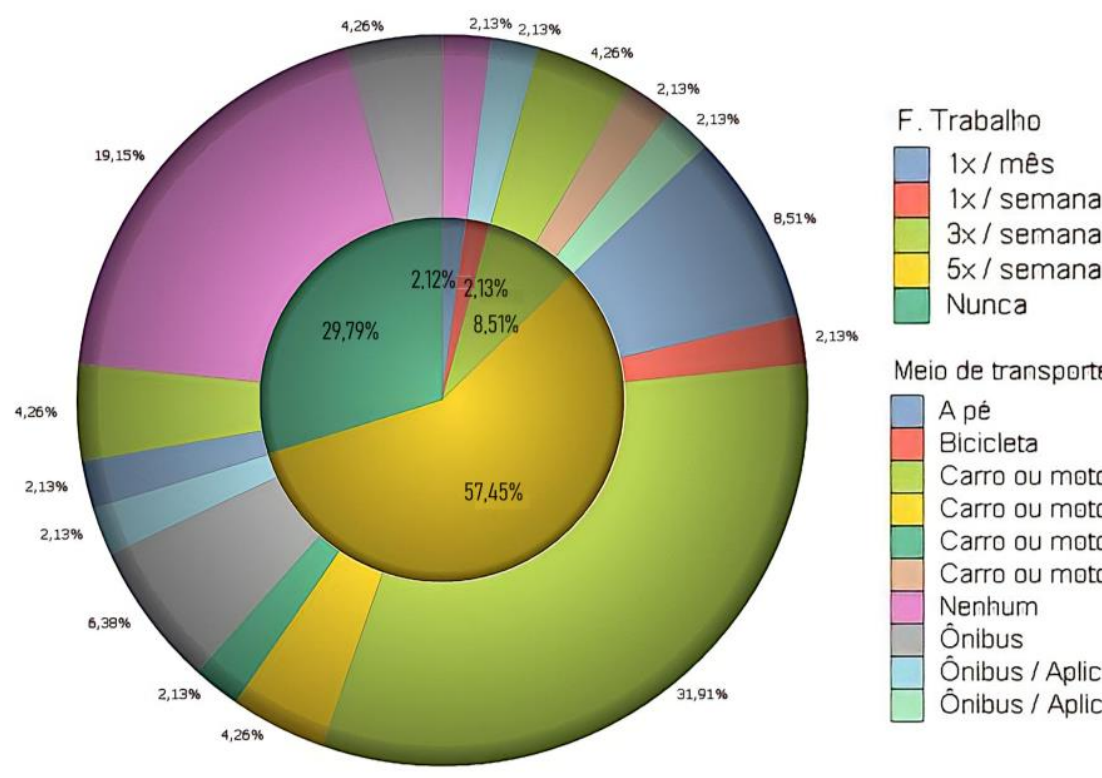

Meio de transporte - Trabalho

A pé
Bicicleta

Carro ou moto

Carro ou moto / A pé

Carro ou moto / Aplicativo de transporte

Carro ou moto / Bicicleta / A pé

Nenhum

Ônibus

Ônibus / Aplicativo de transporte

Ônibus / Aplicativo de transporte / Bicicleta

Fonte - Autores, 2019.

$\begin{array}{lllll}\text { Caminhos de Geografia } \quad \text { Uberlândia-MG } & \text { v. 21, n. } 78 & \text { Dez/2020 } & \text { p. 303-324 Página } 314\end{array}$


Figura 14 - Uberlândia (MG): Viagens para trabalho: por escolaridade - Pós-graduação, 2019.

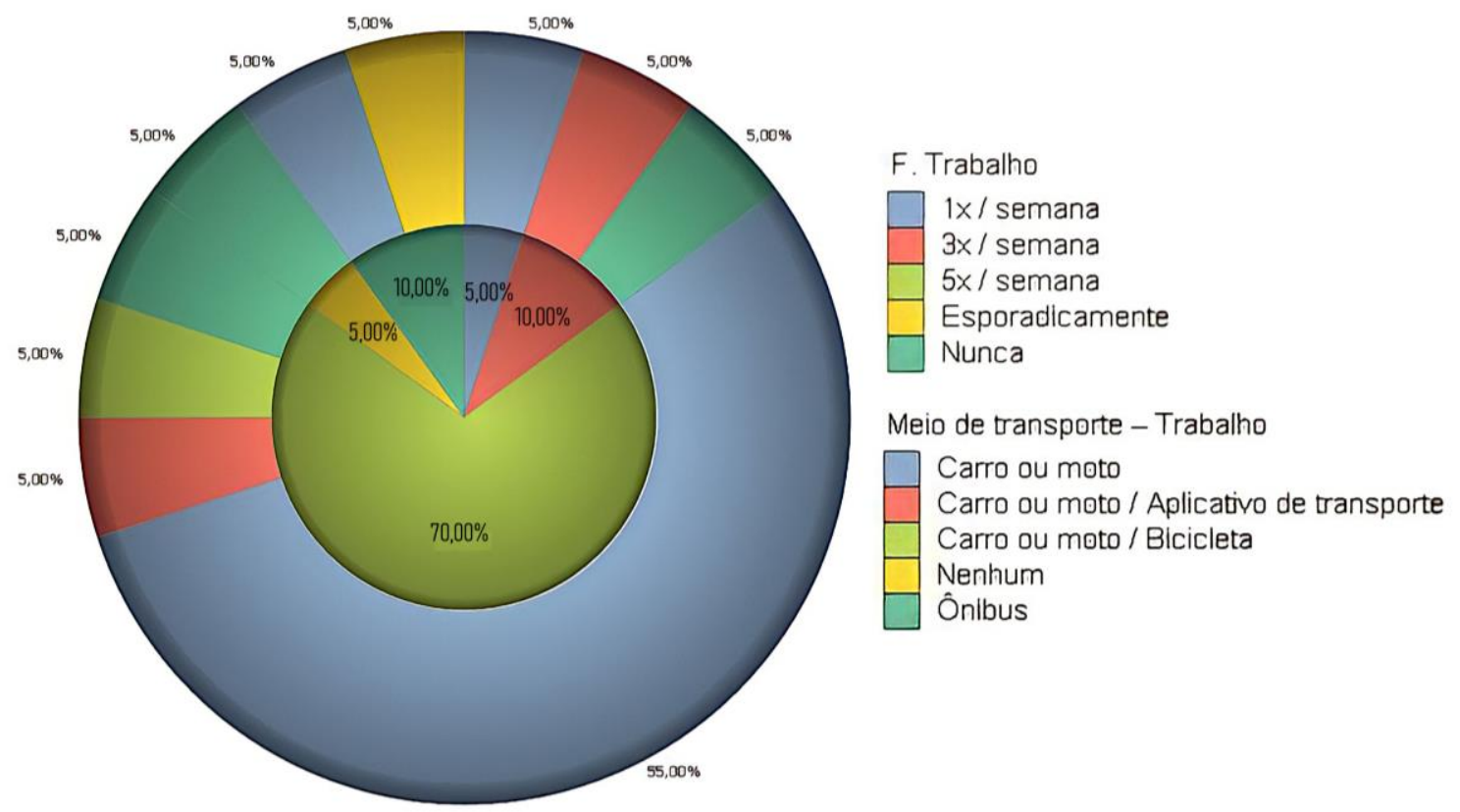

Fonte - Autores, 2019.

A seguir, são feitas as análises a partir das viagens geradas pelos deslocamentos a escolas ou instituições de ensino. Do total de entrevistados, $54,88 \%$ vão cinco vezes na semana; $9,76 \%$ três vezes na semana; $7,32 \%$ uma vez na semana; $1,22 \%$ uma vez ao mês; $4,88 \%$, esporadicamente e $21,95 \%$ não frequentam, seja para estudar ou para levar outra pessoa na instituição de ensino. Pela Figura 15, carro ou moto tem $45,13 \%$ de uso; ônibus, $15,86 \%$; a pé, $13,42 \%$; aplicativo de transporte, 7,32\%; bicicleta, 3,66\%; e nenhum, $18,29 \%$.

Figura 15 - Uberlândia (MG): Viagens para escola: frequência e meios de transporte, 2019.

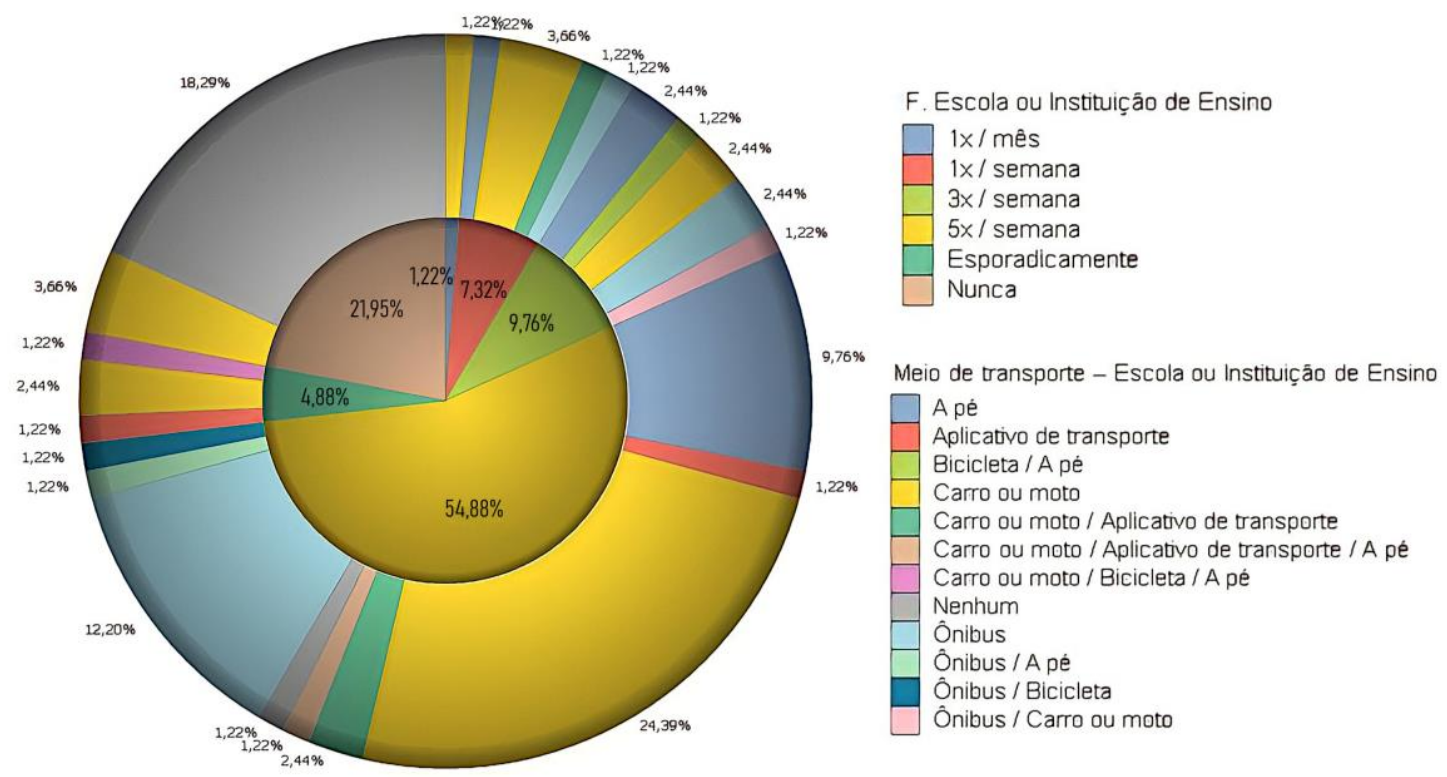

Fonte - Autores, 2019. 
Pelas Figuras 16 e 17, percebe-se que tanto no gênero feminino quanto no masculino, as maiores frequências são de pessoas que se deslocam cinco vezes na semana e das que nunca se deslocam: $53,57 \%$ e $23,21 \%$, respectivamente, no feminino; e $56,00 \%$ e $20,00 \%$, respectivamente, no masculino. Do gênero feminino, os meios de transporte são mais diversificados e combinados entre si, como carro ou moto e aplicativo de transporte, ou ônibus e a pé. Já para os homens, o uso do automóvel particular $(60,00 \%)$ é bem mais frequente que o segundo, o ônibus $(12,00 \%)$, e os usos são pouco variados.

Figura 16 - Uberlândia (MG): Viagens para escola: por gênero - feminino, 2019.

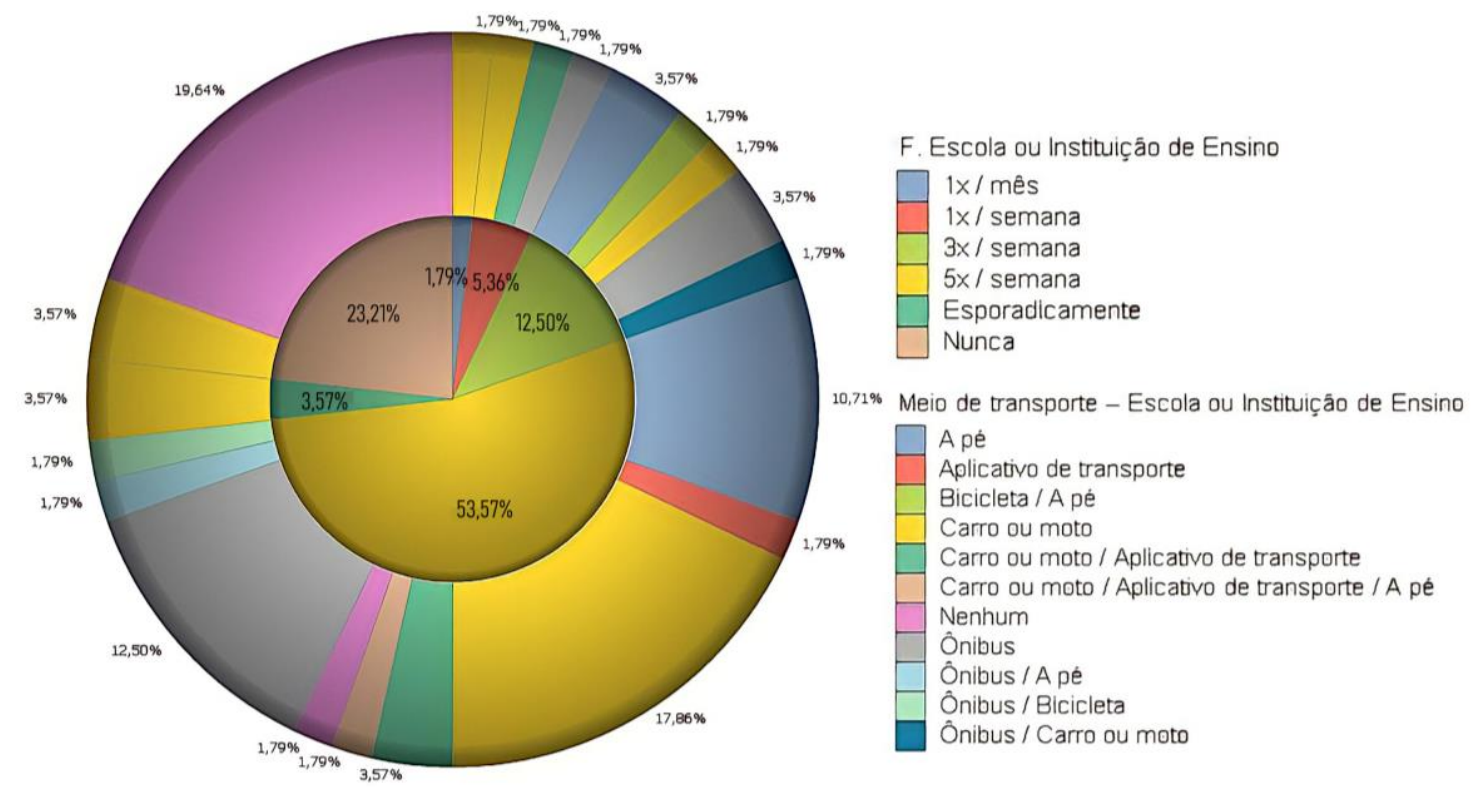

Fonte - Autores, 2019.

Figura 17 - Uberlândia (MG): Viagens para escola: por gênero - masculino, 2019.
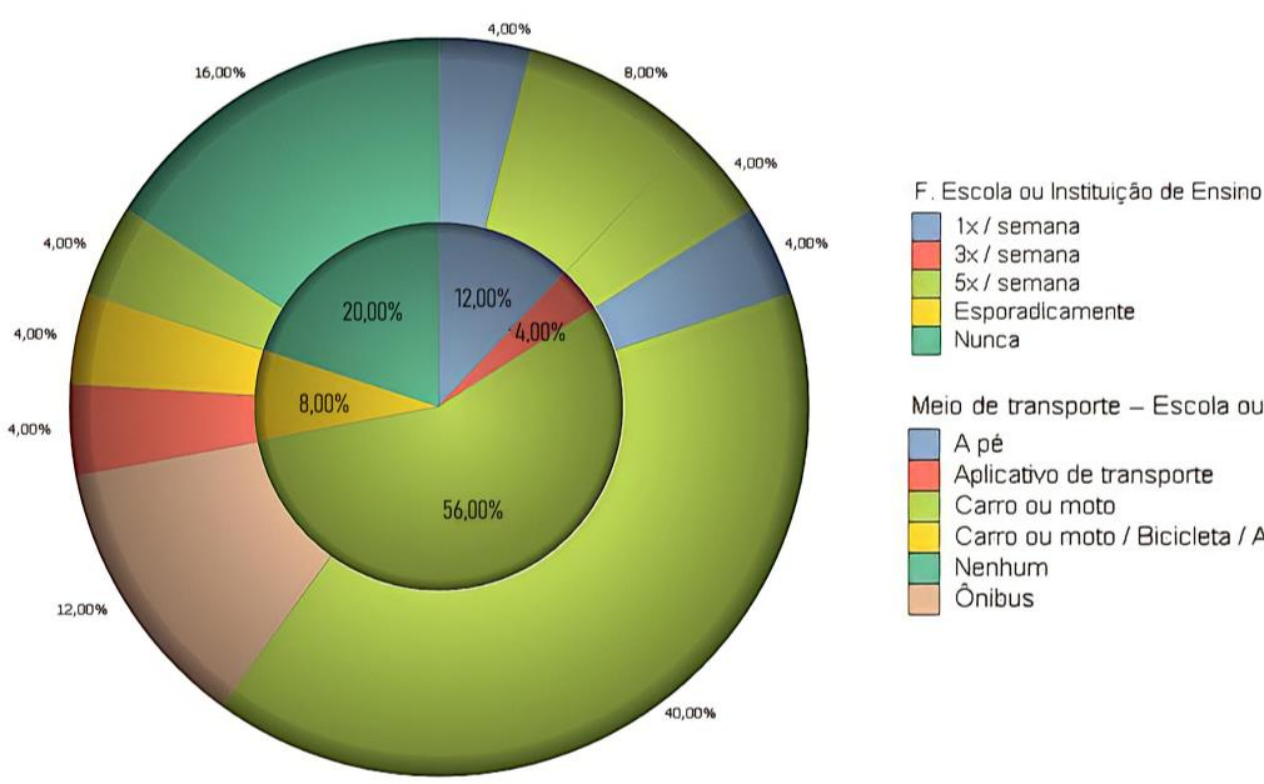

Meio de transporte - Escola ou Instituição de Ensino

A pé

Aplicativo de transporte

Carro ou moto

Carro ou moto / Bicicleta / A pé

Nenhum

Ônibus

Fonte - Autores, 2019. 
No quesito faixa etária (Figuras 18, 19 e 20), dos 19 aos 29 anos, a frequência com que se deslocam cinco vezes na semana é de $68,09 \%$; dos 30 aos 50 anos é de $38,46 \%$; e acima dos 50 anos é de $33,33 \%$. Ou seja, as pessoas tendem a completar os estudos quando são mais novas, não só a escola como também os outros níveis de ensino. É possível ver que, assim como ocorre nos deslocamentos de trabalho, os respondentes mais novos usam vários tipos de meios de transporte, diversificados entre si, entre eles bicicleta e a pé, e carro ou moto e aplicativo de transporte. Além disso, as viagens a pé diminuem de $23,41 \%$ de 19 a 29 anos, a $11,55 \%$ de 30 a 50 anos e a $0,00 \%$ acima de 50 anos.

Figura 18 - Uberlândia (MG): Viagens para escola: por faixa etária - 19 a 29 anos, 2019.

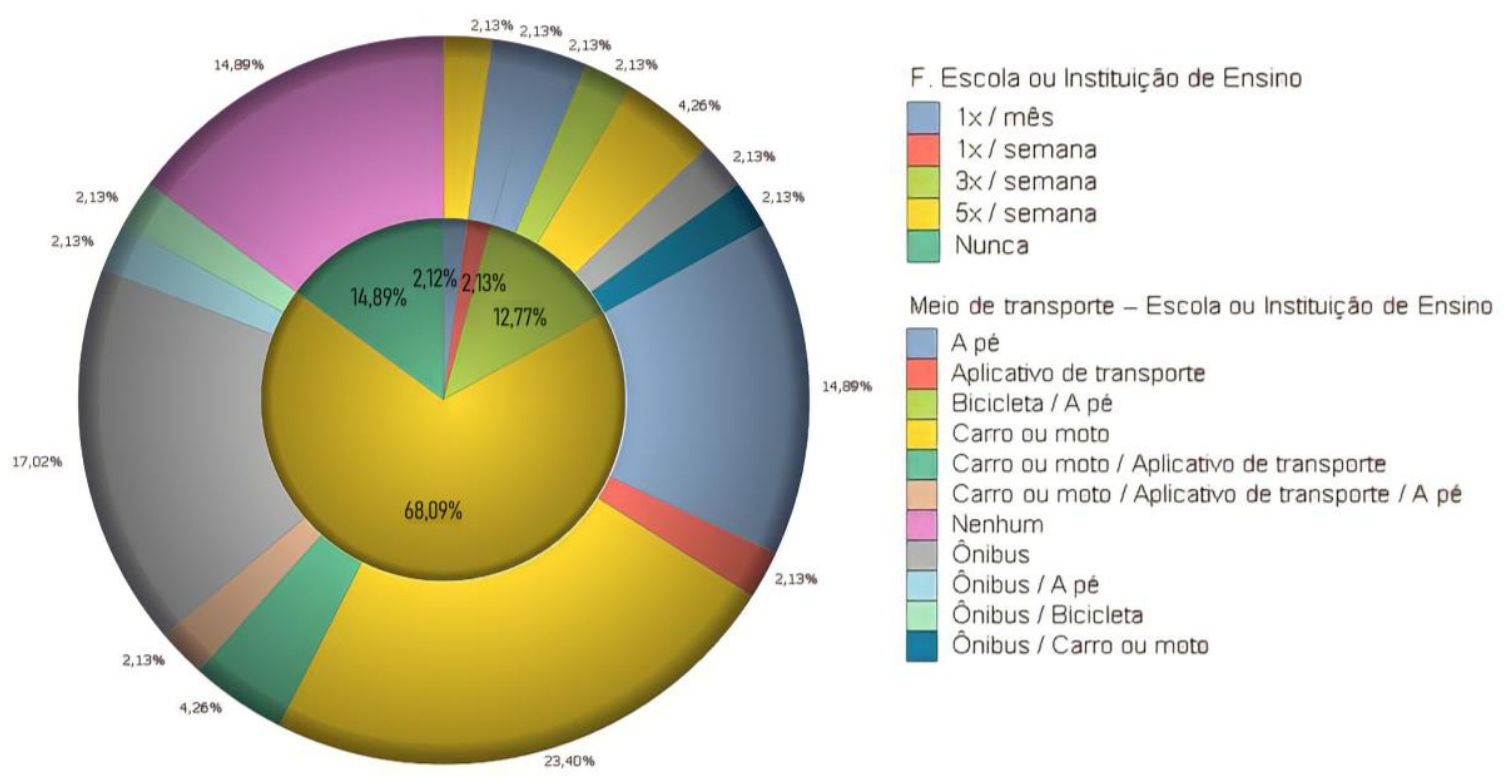

Fonte - Autores, 2019

Figura 19 - Uberlândia (MG): Viagens para escola: por faixa etária - 30 a 50 anos, 2019.

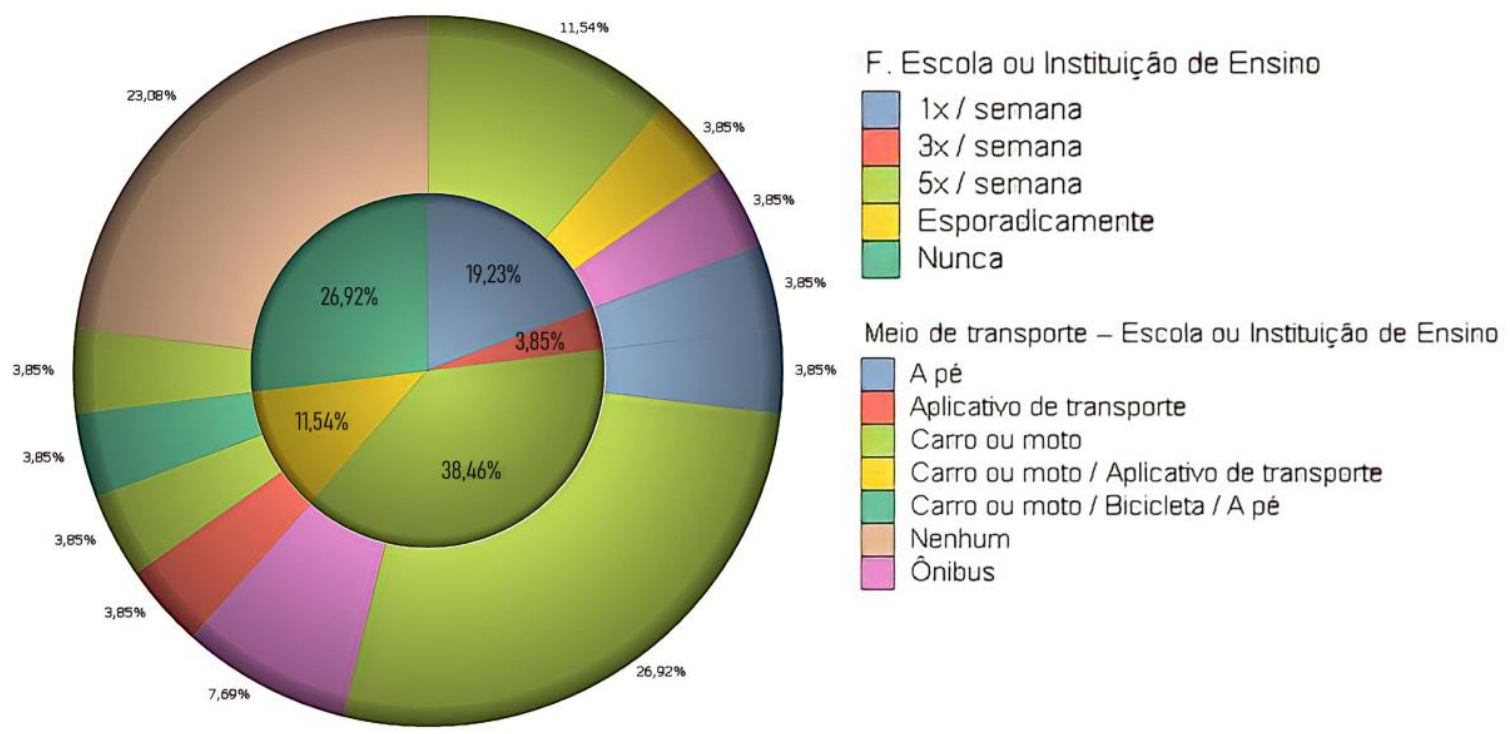

Fonte - Autores, 2019. 
Figura 20 - Uberlândia (MG): Viagens para escola: por faixa etária - acima de 50 anos, 2019.

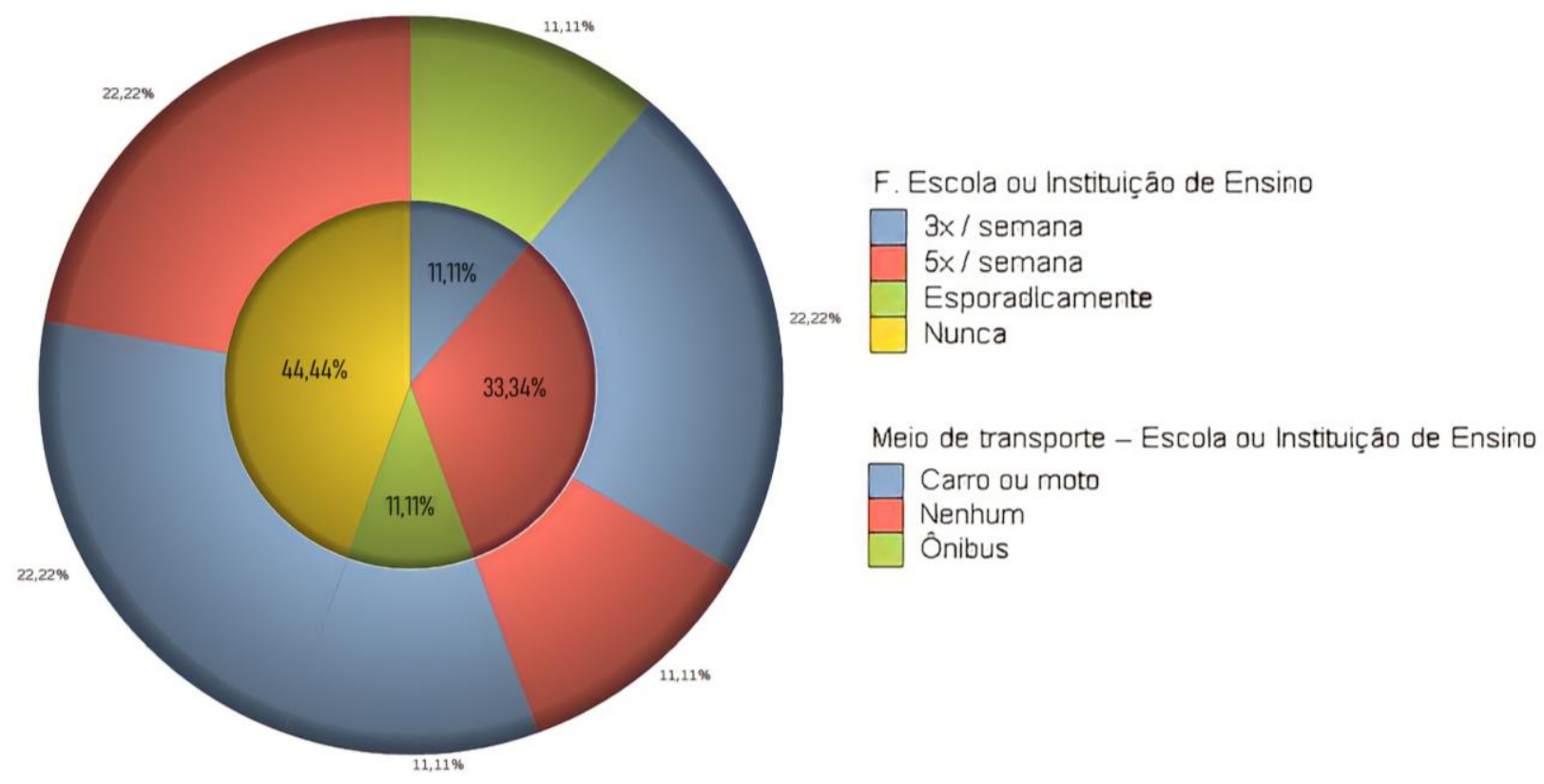

Fonte - Autores, 2019.

A partir da renda familiar (Figuras 21, 22, 23, 24 e 25), é notório que o uso do carro ou moto é condicionado pela maior renda, já que, entre os que recebem até $\mathrm{R} \$ 1.000,00$, apenas $14,29 \%$ faz uso do mesmo, e a maioria utiliza ônibus $(42,86 \%)$, aplicativo de transporte $(14,29 \%)$ ou caminha $(42,86 \%)$. Enquanto isso, na maior renda analisada, carro ou moto corresponde a $52,18 \%$, a pé $21,74 \%$, aplicativo de transporte $8,70 \%$, e ônibus e bicicleta $4,35 \%$. Já quanto à frequência dos deslocamentos, a maioria vai cinco vezes na semana, inclusive a menor renda é totalmente incluída $(100,00 \%)$ nessa opção, chegando a $26,67 \%$ nos que ganham de $R \$ 3.000,00$ a $R \$ 5.000,00$ por mês.

Figura 21 - Uberlândia (MG): Viagens para escola: por renda de até $\mathrm{R} \$ 1.000,00,2019$.

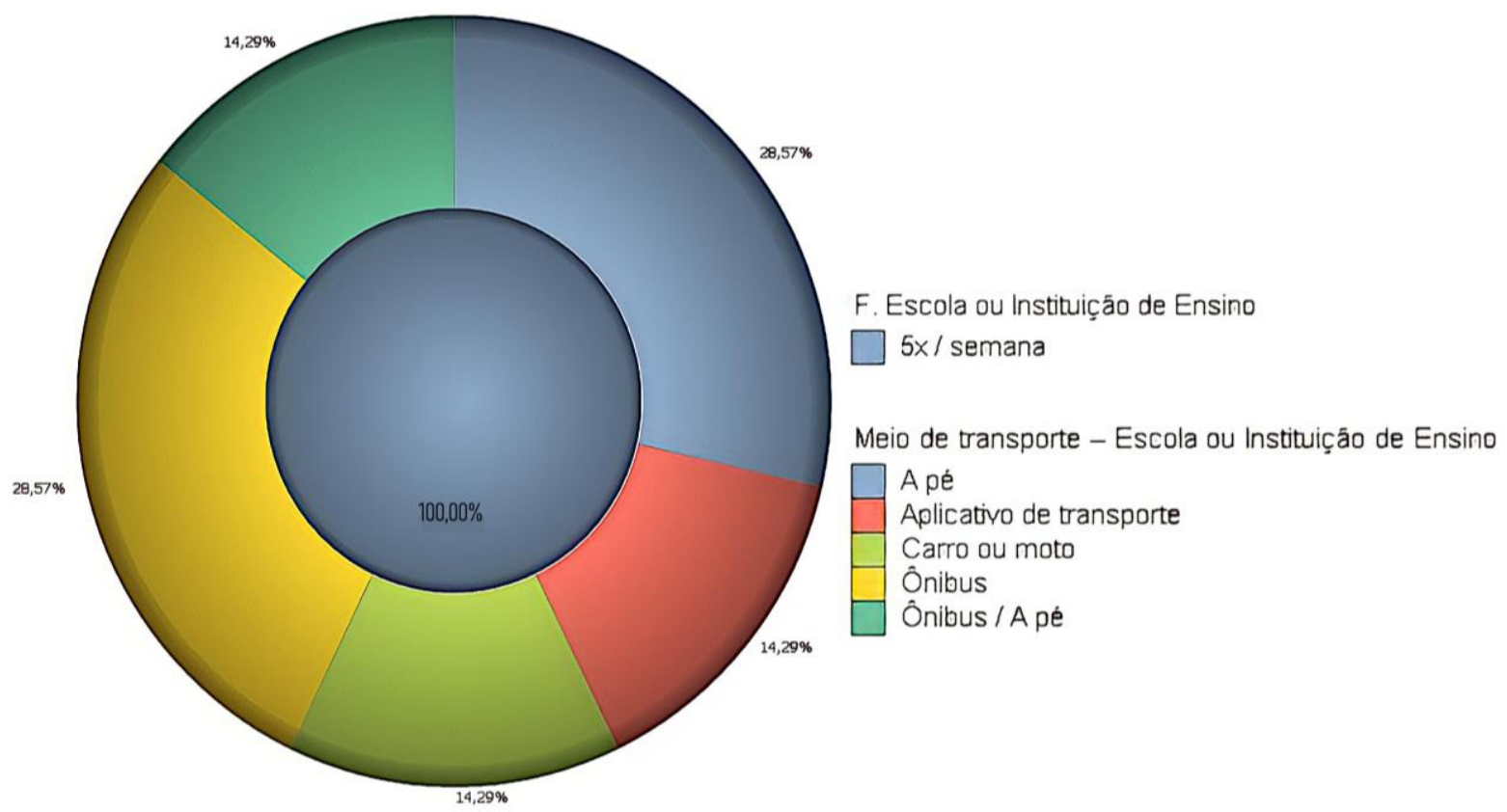

Fonte - Autores, 2019.

$\begin{array}{lllll}\text { Caminhos de Geografia } \quad \text { Uberlândia-MG } & \text { v. 21, n. } 78 & \text { Dez/2020 } & \text { p. 303-324 Página } 318\end{array}$


Figura 22 - Uberlândia (MG): Viagens para escola: por renda de $\mathrm{R} \$ 1.000,00$ a $\mathrm{R} \$ 3.000,00,2019$.

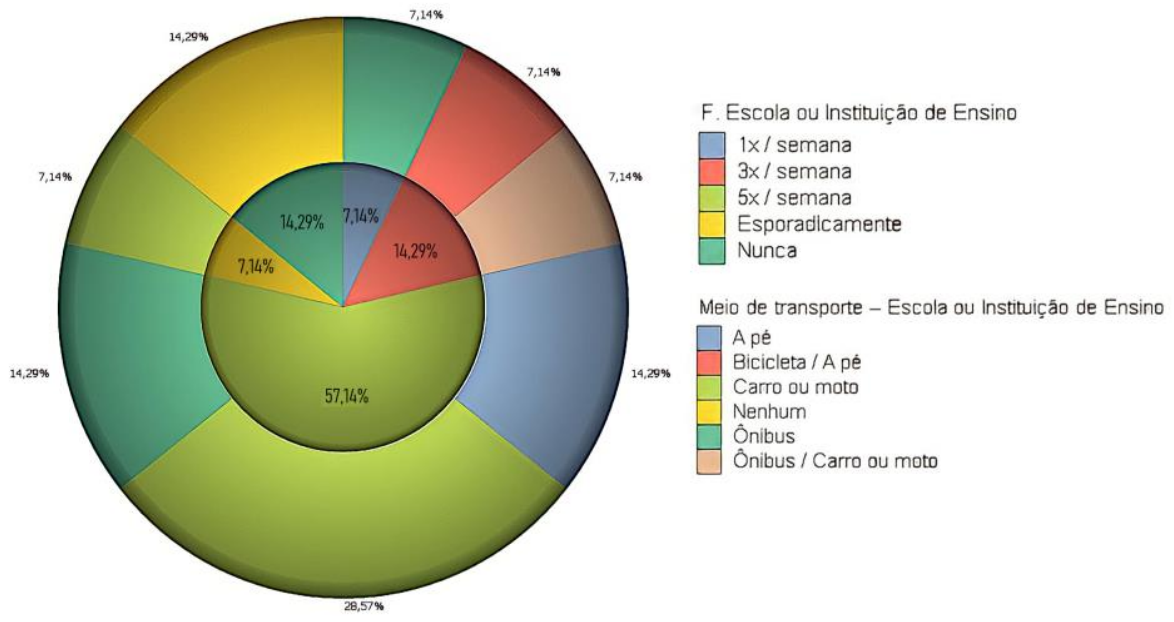

Fonte - Autores, 2019.

Figura 23 - Uberlândia (MG): Viagens para escola: por renda de $\mathrm{R} \$ 3.000,00$ a $\mathrm{R} \$ 5.000,00,2019$.

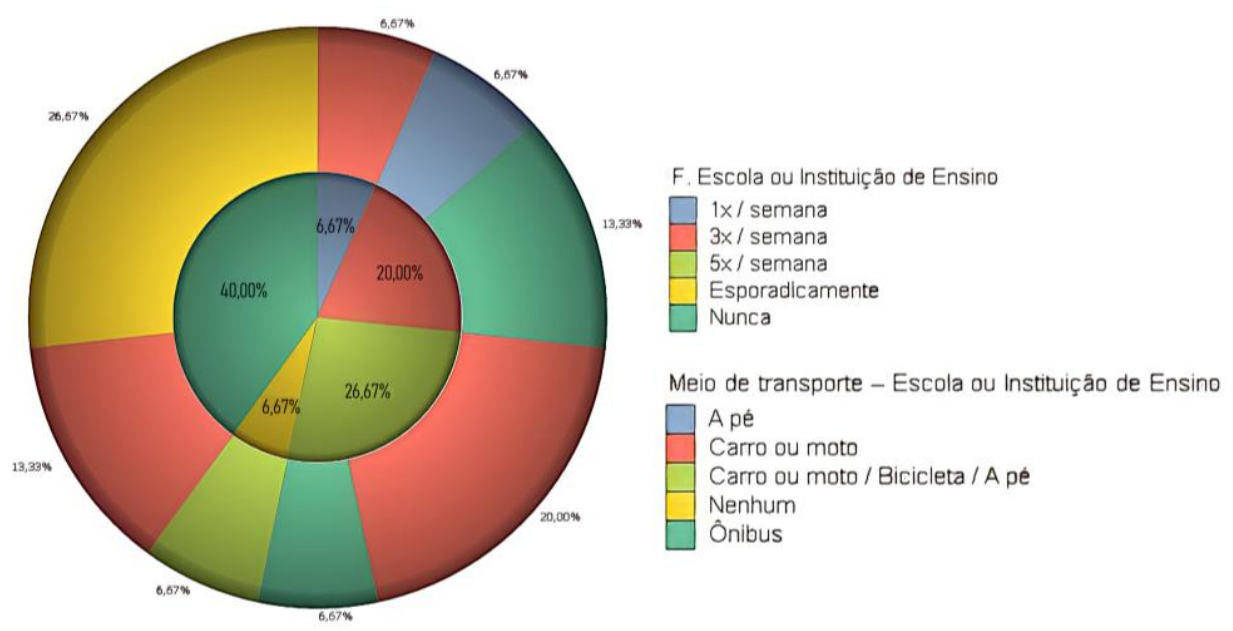

Fonte - Autores, 2019.

Figura 24 - Uberlândia (MG): Viagens para escola: por renda de $R \$ 5.000,00$ a $R \$ 10.000,00,2019$.

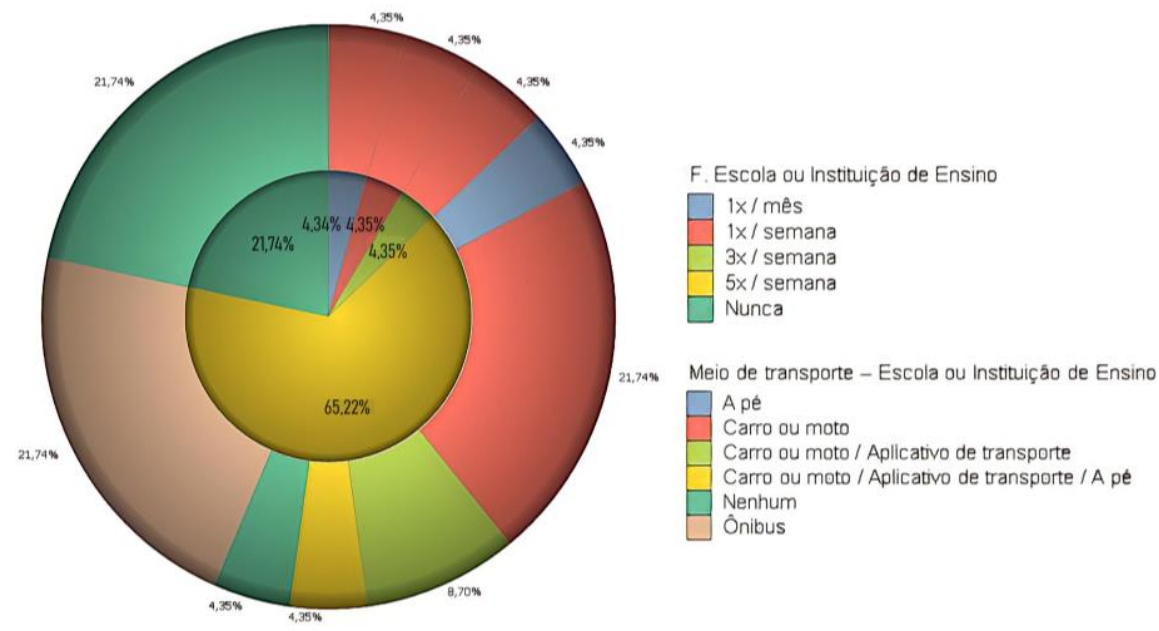

Fonte - Autores, 2019.

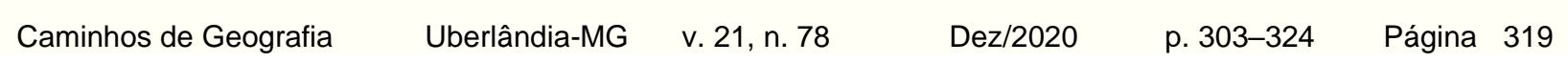


Figura 25 - Uberlândia (MG): Viagens para escola: por renda acima de $\mathrm{R} \$ 10.000,00,2019$.
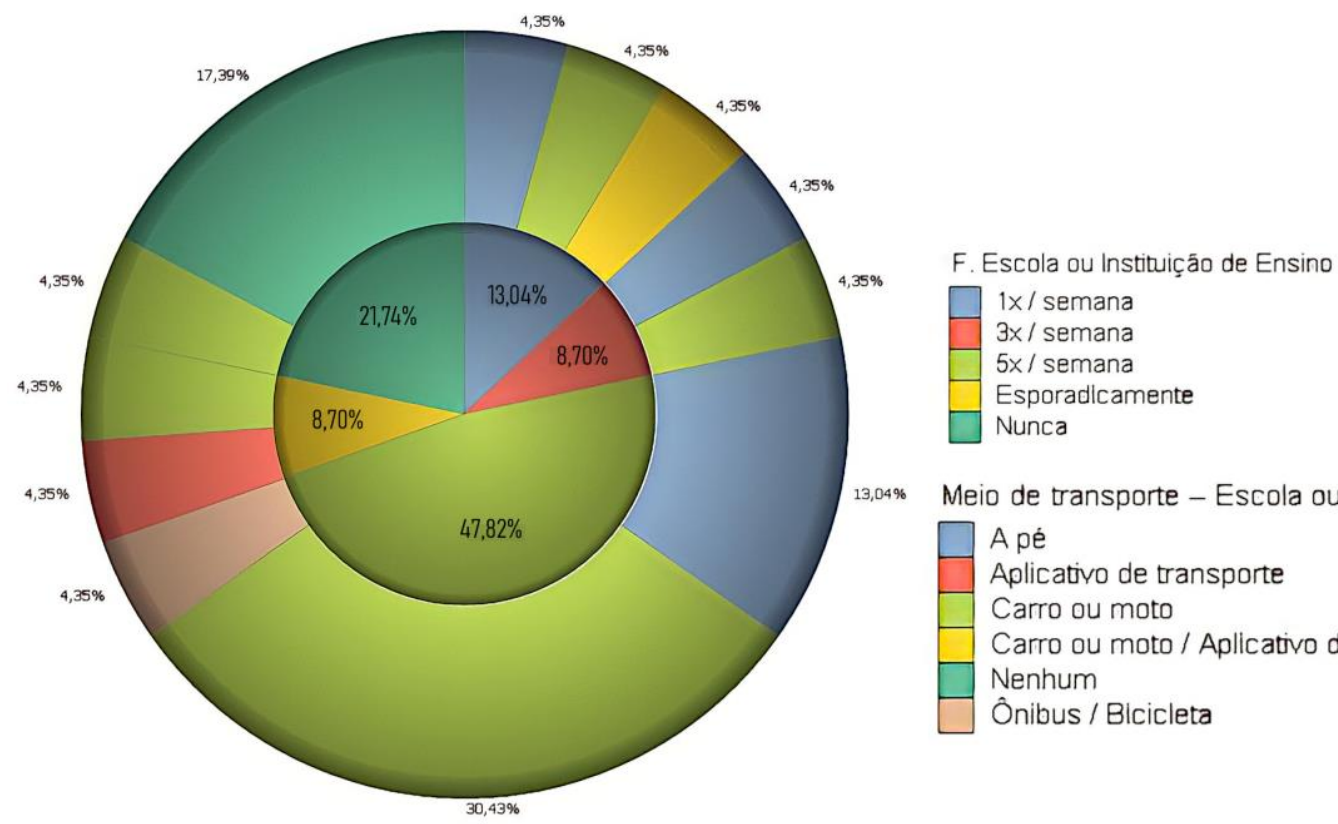

Fonte - Autores, 2019.

Por fim, o questionamento do nível de escolaridade atrelado à ida à escola ou instituição de ensino, presente nas Figuras 26, 27 e 28, mostra que, as pessoas que possuem ensino médio frequentam mais as instituições cinco vezes na semana $(80,00 \%)$, seja para levar alguém ou para concluir outro nível. Já $61,70 \%$ dos que possuem ensino superior vão cinco vezes na semana e $20,00 \%$ dos que têm pós-graduação vão todos os dias úteis. Quanto ao deslocamento, ônibus (40,00\%) supera carro ou moto $(33,34 \%)$ nos entrevistados com ensino médio; e carro é mais frequente nos ensinos superior e pós-graduação: $44,69 \%$ e $55,00 \%$, respectivamente.

Figura 26 - Uberlândia (MG): Viagens para escola: por escolaridade - Ensino Médio, 2019.

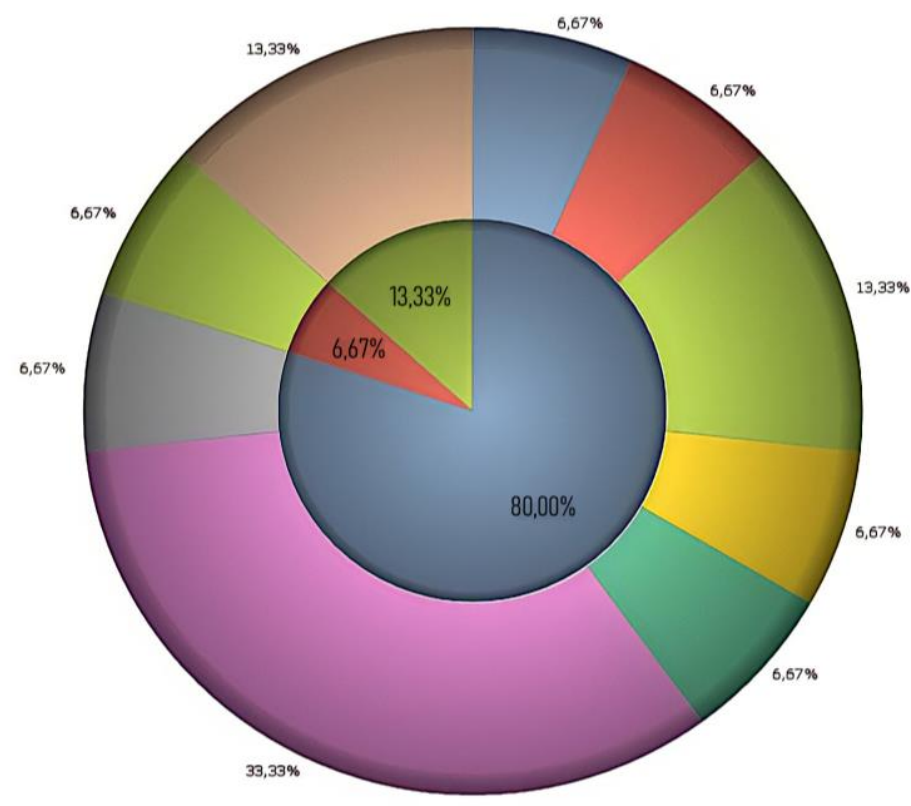

F. Escola ou Instituiçấo de Ensino

$\square 5 x /$ semana

Esporadicamente

Nunca

Meio de transporte - Escola ou Instituição de Ensino

$\square$ A pé

Aplicativo de transporte

Carro ou moto

Carro ou moto / Aplicativo de transporte

Carro ou moto / Aplicativo de transporte / A pé

Nenhum

Ônibus

Ônibus / A pe

Fonte - Autores, 2019.

\begin{tabular}{|c|c|}
\hline Caminhos de Geografia & Uberlândia-MG \\
\hline
\end{tabular}


Figura 27 - Uberlândia (MG): Viagens para escola: por escolaridade - Ensino Superior, 2019.

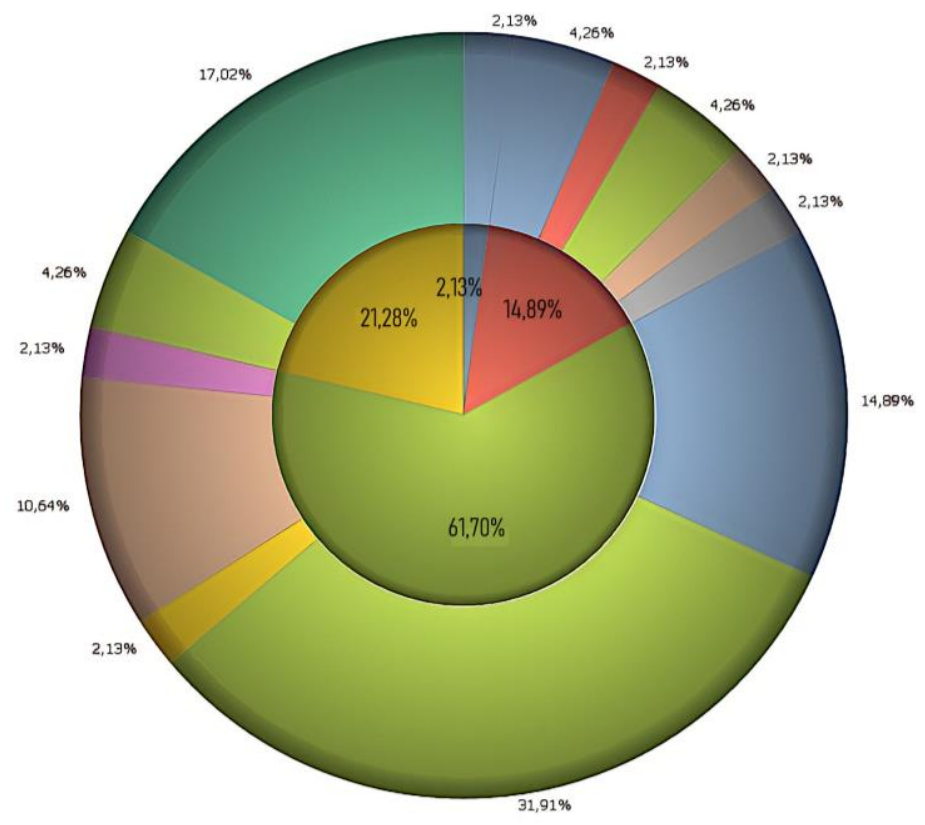

F. Escola ou Instituição de Ensino

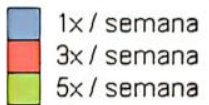

Nunca

Meio de transporte - Escola ou Instituiçâo de Ensino
\begin{tabular}{|l} 
A pé \\
Bicicleta / A pé \\
Carro ou moto \\
Carro ou moto / Aplicativo de transporte \\
Nenhum \\
Ônibus \\
Ônibus / Bicicleta \\
Ônibus / Carro ou moto
\end{tabular}

Fonte - Autores, 2019.

Figura 28 - Uberlândia (MG): Viagens para escola: por escolaridade - Pós-graduação, 2019.

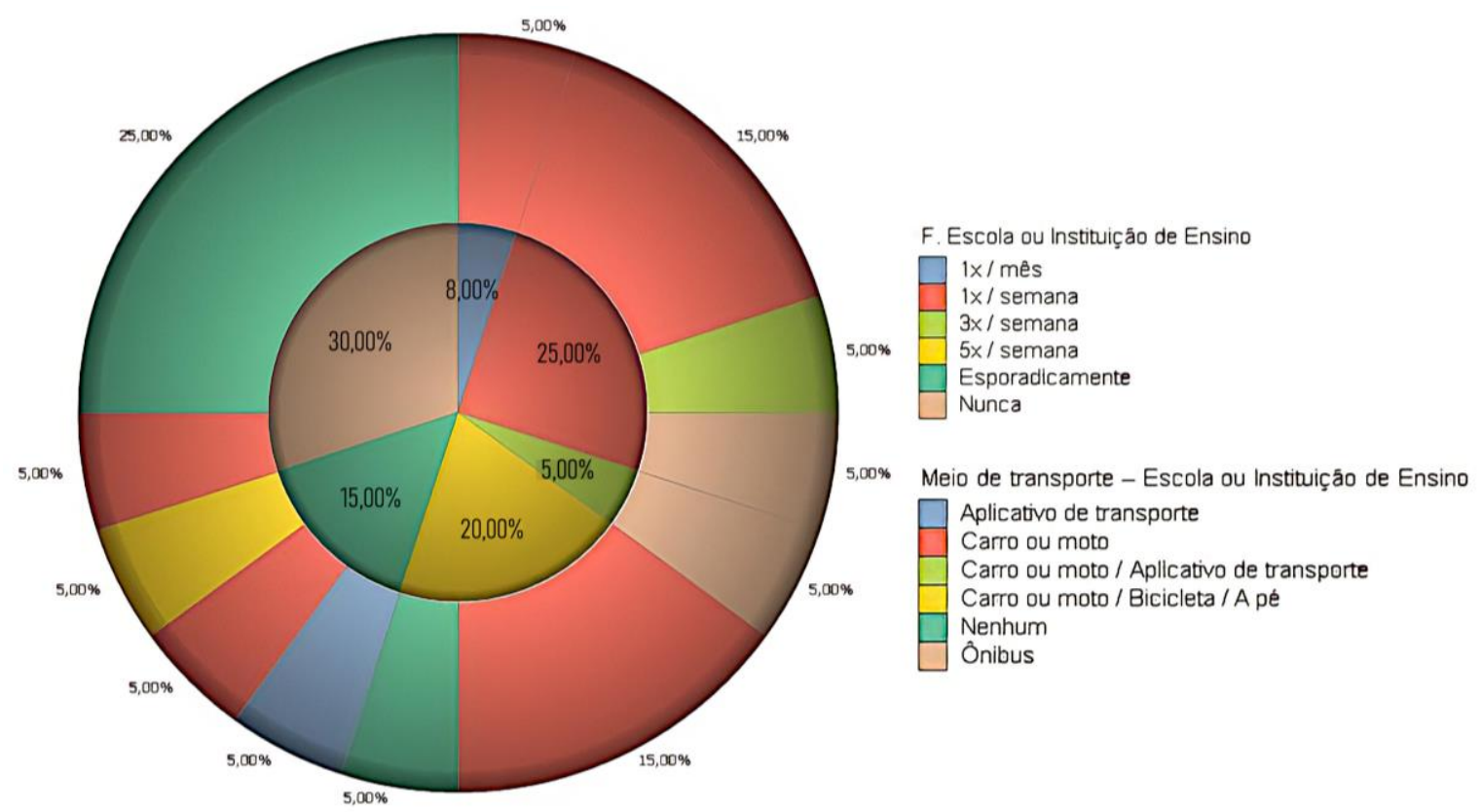

Fonte - Autores, 2019.

\section{CONCLUSÃO}

A partir dos resultados, foi possível concluir que a prevalência do uso do automóvel continua sendo a tônica nos padrões de viagens para trabalho e escola, restando evidente praticamente na totalidade destas análises. A renda e a escolaridade também aparecem vinculadas a essa tendência de uso do automóvel que aumenta na mesma medida. Já nas famílias com rendas mais baixas, a opção pelos transportes coletivos é maior.

$\begin{array}{lllll}\text { Caminhos de Geografia } \quad \text { Uberlândia-MG } & \text { v. 21, n. } 78 & \text { Dez/2020 } & \text { p. 303-324 Página } 321\end{array}$


Os dados refletem o modelo de desenvolvimento urbano marcado pelo rodoviarismo e por uma produção espacial excludente, periferizada e de baixa densidade. Dessa forma, ressalta-se o ciclo vicioso que se inicia com a moradia mal localizada aliada à baixa mobilidade por transportes coletivos. As diferenças de renda também se refletem nas distancias percorridas. Entrevistados com renda mais baixa percorrem maiores distâncias do que os de maior renda. Sem renda para comprar um automóvel, essa parcela menos favorecida fica sem alternativas que se locomover por ônibus, bicicletas ou a pé. Note-se que ao optar pelos meios ativos, esses moradores irão se deparar com uma infraestrutura precária e insegura.

Por outro lado, parcelas de renda maior, parecem não ver motivos para utilizar outros meios de transporte que não o automóvel, já que muitos recursos são destinados a prover infraestrutura para esse modal.

A pesquisa também constatou o aumento da utilização e transportes por aplicativo em todas as faixas de renda, concentrando-se na faixa etária de 19 a 29 anos. A esse respeito, nota-se que para corridas com a partir de 3 passageiros, os aplicativos conseguem competir com a tarifa de ônibus e, em muitos casos tornando-se mais vantajosos. Ao concorrer com o sistema de ônibus, o sistema por aplicativo tende a contribuir para uma maior diminuição e menor atratividade dos transportes coletivos, tornando-os menos atraentes e com isso contribuindo para 0 aumento dos congestionamentos, acidentes e emissões de poluentes. Os resultados indicam, portanto, uma piora em relação à mobilidade, apontando para a urgente revisão das políticas públicas e ações nesse quesito em Uberlândia. Também requer uma revisão na localização e desenho de empreendimentos de habitação social, de forma que eles possam estar mais próximos dos polos empregadores, bem como serem melhor providos de estabelecimentos comerciais e de serviços.

Por fim, os resultados analisados nos permitem concluir que há diversas variáveis na definição dos padrões de viagem da população com peculiaridades conforme sua região geográfica, aspectos socioeconômicos e culturais e ainda a idade. Apontam, também, para a necessidade de utilização de ferramentas de processamento de Big Data, a fim de se obter maior eficácia no cruzamento e processamento de um número grande e mais relevante de informações. A partir das análises desenvolvidas neste artigo, espera-se contribuir com as decisões de planejamento urbano derivadas dos órgãos públicos e privados, principalmente no que diz respeito aos impactos causados pelos deslocamentos diários derivados das viagens para trabalho e escola/instituições de ensino. Assim, também pode ser utilizado como referência a outras pesquisas do gênero e mitigar soluções condizentes com a realidade de cada lugar, de forma a melhorar o cotidiano e o bem-estar de seus cidadãos.

\section{AGRADECIMENTOS}

Os autores agradecem ao Conselho Nacional de Desenvolvimento Científico e Tecnológico - CNPq pelo apoio, o que tornou possível a realização desta pesquisa.

\section{REFERÊNCIAS}

ACHEAMPONG, R. A.; SILVA, E. A. Land use-transport interaction modeling: A review of the literature and future research directions. The Journal of transport and land use, v. 08, n. 03, p. 1138, 2015. https://doi.org/10.5198/itlu.2015.806

ALVES, P.; FERREIRA, W. R. Mobilidade urbana e traffic calming. Caminhos de Geografia, Uberlândia, v. 15, n. 51, p. 60-72, 2014. 2 Disponível em: http://www.seer.ufu.br/index.php/caminhosdegeografia/article/view/26902/15459. Acesso em: 3 out 2020.

BERTAZZO, A. B. S. Estimativa e avaliação do padrão de viagens geradas para instituições de ensino médio. Dissertação de Mestrado. Brasília: Universidade de Brasília, 198 p., 2008.

BOARETO, R. A mobilidade urbana sustentável. Revista dos Transportes Públicos - ANTP. São Paulo, Ano 25, 3o trim, n. 100, p. 45-56, 2003. Disponível em: http://files- 
server.antp.org.br/ 5dotSystem/download/dcmDocument/2013/01/10/15FBD5EB-F6F4-4D95-B4C46AAD9C1D7881.pdf. Acesso em: 6 ago 2020.

BRASIL. Ministério das Cidades. Lei no 12.587 de 3 de janeiro de 2012: Política Nacional de Mobilidade Urbana. Brasília, 2012. Disponível em: http://www.planalto.gov.br/ccivil 03/ ato20112014/2012/lei/112587.htm. Acesso em: 03 out 2020.

BULIUNG, R. N.; HERNANDEZ, T.; MITCHELL, J. E. Exploring the relationship between Big-Box retail and consumer travel demand in the Greater Toronto Area. Canadian Journal of Transportation, Calgary, v. 01, n. 02, p. 121-141, 2007.

CÂMARA, G.; MONTEIRO, A. M. V.; MEDEIROS, J. S. Representações computacionais do espaço: um diálogo entre a Geografia e a Ciência da Geoinformação. São José dos Campos: Divisão de Processamento de Imagens, Instituto Nacional de Pesquisas Espaciais (DPI/INPE), 2001.

CERVERO, R.; WU, K. L. Sub-centering and commuting: evidence from the San Francisco Bay Area. Urban Studies, v. 35, p. 1059-1076, 1998. https://doi.org/10.1080/0042098984484

COMPANHIA DE ENGENHERIA DE TRÁGEGO (CET). Pólos Geradores de Tráfego. Boletim Técnico 32. Prefeitura do Município de São Paulo. 1983. Disponível em: http://www.cetsp.com.br/media/65486/bt32-\%20polos\%20geradores\%20de\%20trafego.pdf. Acesso em: jul 2019.

COX, K. R. Man, Location and Behavior: An Introduction to Human Geography. New York: John Wiley \& Sons, 1972.

FERREIRA, M. C. Iniciação à análise geoespacial: teoria, técnicas e exemplos para geoprocessamento. São Paulo: Editora Unesp, 2014.

FRÚGOLI JR., H. Shopping Centers: um olhar antropológico. In: PINTAUDI, S. M. e FRÚGOLI JR., H. Shopping centers: espaço, cultura e modernidade nas cidades brasileiras. São Paulo: UNESP, 1992.

GARREFA, F. Shopping Centers: de centro de abastecimento a produto de consumo. São Paulo: SENAC, 2011.

HARDWICK, M. J. Mall maker: Victor Gruen, architect of an American dream. Filadélfia: University of Pennsylvania Press, 2004.

HERZ, M.; GALARRAGA, J.; PASTOR, G. Características de Generación y Distribución Modal de Viajes en centros Educativos Universitarios. XV CLATPU Congreso Latinoamericano de Transporte Público y Urbano, Buenos Aires, 2009.

HERZ, M.; GALARRAGA, J.; PASTOR, G. Centros universitarios como Polos Generadores de Viajes. XIV CLATPU Congreso Latinoamericano de Transporte Público y Urbano, Río de Janeiro, 2007.

INSTITUTO NACIONAL DE ESTATÍTICA. Gabinete de Estudos e Planejamento. Movimentos Pendulares e Organização do Terrítório Metropolitano: Áreas Metropolitana de Lisboa e Área Metropolitana do Porto, 1991-2001. Lisboa: INE, 2003.

ITE - Institute of Transportation Engineers. Trip Generation, 8th Edition, Washington, D.C, 2008.

JACQUES, M. A. P.; BERTAZZO, A.; CALARRAGA, J.; HERZ, M. Nova abordagem para o estudo das viagens geradas nas instituições de ensino. Transportes, vol. 18, n. 01, p. 75-85, 2010. https://doi.org/10.14295/transportes.v18i1.385

KNEIB, E. C.; TACO, P. W. G.; DA SILVA, P. C. M. Identificação e avaliação de impactos na mobilidade: análise aplicada a pólos geradores de viagens. Rede PGVs. 2006. Disponível em: http://www.redpgv.coppe.ufrj.br/index.php/es/produccion/articulos-cientificos/2006-1/250-kneib-tacosilva-pluris2006/file. Acesso em: jul 2019.

LIMA NETO, V. C.; NADALIN, V. G. O impacto da formalidade do trabalho e da inserção urbana no deslocamento casa-trabalho: uma análise intraurbana para cinco espaços metropolitanos. In: BALBIM, R.; KRAUSE, C.; LINKE, C. C. Cidade e movimento: mobilidades e interações no desenvolvimento urbano. Brasília: Ipea: ITDP, 326 p., 2016.

LONGLEY, P. A.; GOODCHILD, M. F.; MAGUIRE, D. J.; RHIND, D. W. Sistemas e Ciência da Informação Geográfica. Porto Alegre: Bookman, 2013, 540 p.

\begin{tabular}{|c|c|}
\hline Caminhos de Geografia & Uberlândia-MG \\
\hline
\end{tabular}


NELSON, R. L. The selection of retail location. New York: Dodge, 1958.

PADILHA, V. Shopping center: a catedral das mercadorias. São Paulo: Boitempo, 2006.

PEARSON, R.; PEARSON, B. The J.C. Nichols Chronicle: the authorized story of the Man and his Company, 1880-1994. Cidade do Kansas: University Press of Kansas, 1994.

PORTUGAL, L.S. e GOLDNER, L. G. Estudo de Pólos Geradores de Tráfego e de seus Impactos nos Sistemas Viários e de Transportes. Editora Edgard Blucher. São Paulo, SP. 2003.

RAIA JR., A. A. Acessibilidade e mobilidade na estimativa de um índice de potencial de viagens utilizando redes neurais artificiais e sistemas de informações geográficas. Tese (Doutorado em Engenharia Civil - Transportes) - Escola de Engenharia de São Carlos. São Carlos: Universidade de São Paulo, 212 p., 2000.

REIS, N. G. Notas sobre urbanização dispersa e outras formas de tecido urbano. São Paulo: Via das Artes, 2006.

RICHARDSON, A.J.; AMPT, E.S. E MEYBURG, A.H. Survey Methods for Transport Planning. Eucalyptus Press, Parkville, Australia, 1995.

RODRIGUES, J.P., COMTOIS, C.; SLACK, B. The Geography of Transport Systems. New York: Routledge, 2006.

SALGUEIRO, T. B. Do comércio a distribuição: roteiro de uma mudança. Lisboa: Celta, 1995. https://doi.org/10.14393/RCG176009

SANTOS, F. R. O capital incorporador e a "nova classe" trabalhadora na produção do espaço urbano: apontamentos teóricos sobre a mobilidade residencial. Caminhos de Geografia, Uberlândia, v. 17, n. 60 , p. 118-130, 2016. DOI: https://doi.org/10.14393/RCG176009. Disponível em: http://www.seer.ufu.br/index.php/caminhosdegeografia/article/view/34101. Acesso em: 3 out. 2020.

SANTOS, M. O espaço do cidadão. São Paulo: Nobel, 1987.

SORKIN, M. (Org.). Variaciones sobre un parque temático: La nueva ciudad americana y el fin del espacio publico. Barcelona: Gustavo Gilli, 2004.

SUN, Y; SILVA, E.; TIAN, W.; TIAN, W.; LENG, H. An integrated spatial analysis computer environment for urban-building energy in cities. Sustainability, v. 10, n. 11, p. 01-19, 2018. https://doi.org/10.3390/su10114235

UBERLÂNDIA. Prefeitura. Secretaria Municipal de Planejamento Urbano. Banco de Dados Integrados: Ano 2019. Uberlândia: Prefeitura de Uberlândia, 2019. Disponível em: http://docs.uberlandia.mg.gov.br/wp-content/uploads/2019/10/BDI-2019-vol1.pdf. Acesso em: 3 out. 2020.

VARGAS, H. C. Espaço terciário: o lugar, a arquitetura e a imagem do comércio. São Paulo: SENAC, 2001.

VASCONCELLOS, E. A. Andar nas cidades do Brasil. In: ANDRADE, V.; LINKE, C. C. (org.). Cidade de Pedestres: A caminhabilidade no Brasil e no Mundo. 1. Ed. Rio de Janeiro: Babilonia Cultura Editorial, 2017. Cap. 4, p. 42-53.

VILLAÇA, F. Espaço intraurbano no Brasil. São Paulo: Studio Nobel, 2001.

YAMAMOTO, J. K.; LANDIM, P. M. B. Geoestatística: conceitos e aplicações. São Paulo: Oficina de Textos, 215 p., 2013.

WALL, A. Victor Gruen: From urban shop to new city. Barcelona: Actar, 2005.

ZHANG, C.; XIAO, C.; LIU, H. Spatial Big Data analysis of political risks along the Belt and Road. Sustainability, v. 11, n. 08, p. 01-16, 2019. https://doi.org/10.3390/su11082216

Recebido em: 26/03/2020

Aceito para publicação em: 28/10/2020 